\title{
Review on estimation methods of the Earth's surface energy balance components from ground and satellite measurements
}

\author{
Md Masudur Rahman ${ }^{1,2}$ and Wanchang Zhang ${ }^{1, *}$ \\ ${ }^{1}$ Key Laboratory of Digital Earth Science, Institute of Remote Sensing and Digital Earth, Chinese Academy of \\ Sciences, Beijing 100 094, People's Republic of China. \\ ${ }^{2}$ University of Chinese Academy of Sciences, Beijing 100 049, People's Republic of China. \\ *Corresponding author. e-mail: zhangwc@radi.ac.cn
}

MS received 20 June 2017; revised 17 March 2018; accepted 19 July 2018; published online 22 March 2019

Accurate estimation of the Earth's surface energy balance (SEB) components is very much important for characterising the environmental, hydrological and bio-geophysical processes to predict the weather and climate or climate change. This narrative review summarises the basic theories of estimation methods of the solar (shortwave) radiation, thermal (longwave) radiation and evapotranspiration (latent heat flux) from both the ground and satellite measurements, which are inherently complex to measure at large scale. This paper discusses the reviews of prior and recent advances in the estimation methods and models by focusing their advantages, disadvantages and recommendations. Uncertainties associated with satellite estimations and some key directions for further studies are also discussed, including the status of ground-based measurements at regional and global scales and the advent of new satellite technologies for quantifying the SEB components more accurately. This study infers that the further advances in the satellite remote sensing and worldwide ground-based measurement networks will enhance the capabilities for the potential estimation of the SEB parameters as well as monitoring the global water and energy cycles to develop significant environmental studies for the betterment of living on the Earth.

Keywords. The Earth's surface; energy balance; solar radiation; thermal radiation; evapotranspiration; estimation methods.

\section{Introduction}

Sun is the primary source of energy on Earth. The incoming solar radiation is distributed in different components due to the scattering, reflecting, transmitting and absorbing characteristics of the Earth's surface and atmosphere. The net radiation is partitioned into sensible heat flux, latent heat flux and soil heat flux i.e. known as the surface energy balance (SEB) which is extremely vital to any land surface models for developing the hydrological, ecological and bio-geophysical processes. The very basic equation of SEB can be expressed as

$$
R_{\mathrm{n}}=G+H+\mathrm{LE},
$$

where $R_{\mathrm{n}}$ is the net radiation in $\mathrm{W} \mathrm{m}^{-2}, G$ is the soil heat flux, $H$ is the sensible heat flux and LE is the latent heat flux. The land surface radiation budgets, i.e., the Earth's SEB between the incoming radiation in both short and longwave spectra 
are characterised by the net radiation $\left(R_{\mathrm{n}}\right)$ which can be expressed as

$$
\begin{aligned}
& R_{\mathrm{n}}=R_{\mathrm{n}}^{\mathrm{s}}+R_{\mathrm{n}}^{\mathrm{l}}, \\
& R_{\mathrm{n}}^{\mathrm{s}}=(1-\alpha) R^{\mathrm{s}} \downarrow, \\
& R_{\mathrm{n}}^{\mathrm{l}}=\varepsilon R^{\mathrm{l}}-\varepsilon \sigma T_{\mathrm{s}}^{4},
\end{aligned}
$$

where $R^{\mathrm{s}} \downarrow$ and $R^{\mathrm{l}} \downarrow$ are the incoming radiation of both shortwave (solar) and longwave (thermal) spectra, respectively, $\alpha$ is the albedo (unit less), $\varepsilon$ is the atmospheric emissivity (unit less), $T_{\mathrm{S}}$ is the surface temperature $(\mathrm{K})$ and $\sigma$ is the Stefan-Boltzmann constant $\left(\mathrm{W} \mathrm{m}^{-2} \mathrm{~K}^{-4}\right)$. Now the sensible heat flux $(H)$ and latent heat flux (LE) can be written in the following equations:

$$
\begin{aligned}
H & =\rho C_{p} \frac{\mathrm{d} T}{r_{\mathrm{ah}}}, \\
\mathrm{LE} & =R_{\mathrm{n}}-G-H,
\end{aligned}
$$

where $\rho$ is the air density $\left(\mathrm{kg} \mathrm{m}^{-3}\right), C_{p}$ is the air specific heat $\left(\mathrm{J} \mathrm{kg}^{-1} \mathrm{~K}^{-1}\right), \mathrm{d} T$ is the temperature difference between air and surface $(\mathrm{K})$ and $r_{\mathrm{ah}}$ is the aerodynamic resistance $\left(\mathrm{s} \mathrm{m}^{-1}\right)$. The above said components of Earth's SEB are responsible for heating or cooling of the land/soil (solar and thermal radiation), the heating and cooling of the air (sensible heat flux) and the evaporation of water from soil and vegetation (latent heat flux). Figure 1 shows an illustration of the Earth's surface radiation and energy flow among the space, atmosphere and Earth's surface.

Figure 1 shows that the incoming solar radiation is reflected and absorbed by the clouds, atmosphere and Earth's surface after that the cloud, atmosphere and Earth's surface emit the thermal radiation along with the other turbulent (soil, sensible and latent heat) fluxes. The net absorbed radiation plays a vital role in the environmental analysis and it should be zero, if not then heating effect for positive value and cooling for negative. To illustrate the energy flows at a global and local view, there were a lot of iconic diagrams that have been presented in the published articles and textbooks (Wild et al. 2009; Stephens and L'Ecuyer 2013; L'ecuyer et al. 2015) based on the conceptual background and several satellite and ground measurements. Trenberth et al. (2009) revealed the measurement of mean Earth's energy budget by a satellite sensor the Clouds and the Earth's Radiant Energy System
(CERES) for the March 2000 to May 2004 period and found that the net absorbed radiation was $0.9 \mathrm{~W} \mathrm{~m}^{-2}$, which simply infers today's global warming issues.

Nowadays, there are more frequent weather anomalies as a consequence of global warming. Due to the interlinked systems, changes in single aspect of global process reverberate through the entire system, e.g., increasing surface temperatures modify the rainfall patterns and evaporation rates, which may lead to floods, droughts and storms, and hurricanes may intense due to the increase in sea surface temperatures. This is the common scenario over several parts of the world and has become an important research question. The study of energy flows between the Earth's surface, the atmosphere and space is of great importance for different types of environmental analysis (Krishnamurti and Biswas 2006; Wang and Liang 2008; Yingying et al. 2008; Xie et al. 2016), including climate change, disaster monitoring, plant water demand, plant growth, productivity, the irrigation management system and also in determining the large-scale atmosphere and ocean circulation patterns which eventually drive weather and climate (Slingo and Slingo 1988; Hartmann 1994; Lee et al. 2001; Schumacher et al. 2004; Bonan 2008). Therefore, we can feel that the effective estimation of land surface radiation and energy components is factually necessary for the Earth and environmental analysis to predict the weather and climate or climate change. However, the estimation of these components is very complex in nature due to the diverse characteristics of the atmosphere and Earth's surface.

To the best of our knowledge, the number of published review articles related to this review work is limited but the existing papers have presented very good and critical review works (Diak et al. 2004; Li et al. 2009; Liang et al. 2010; Nouri et al. 2013; Liou and Kar 2014; Shi et al. 2015; Zhang et al. 2016, etc.), which are reflecting the excellent state of art in the estimation techniques of surface energy fluxes. They reviewed the estimation methods of surface flux components in terms of history, measurement methods, merits and demerits of the methods and also focused on some experimental results. Most of the studies focused on one component such as evapotranspiration (ET, latent heat flux) based on the satellite estimation techniques, whereas we focus on the three important components (solar radiation, thermal radiation and ET) 

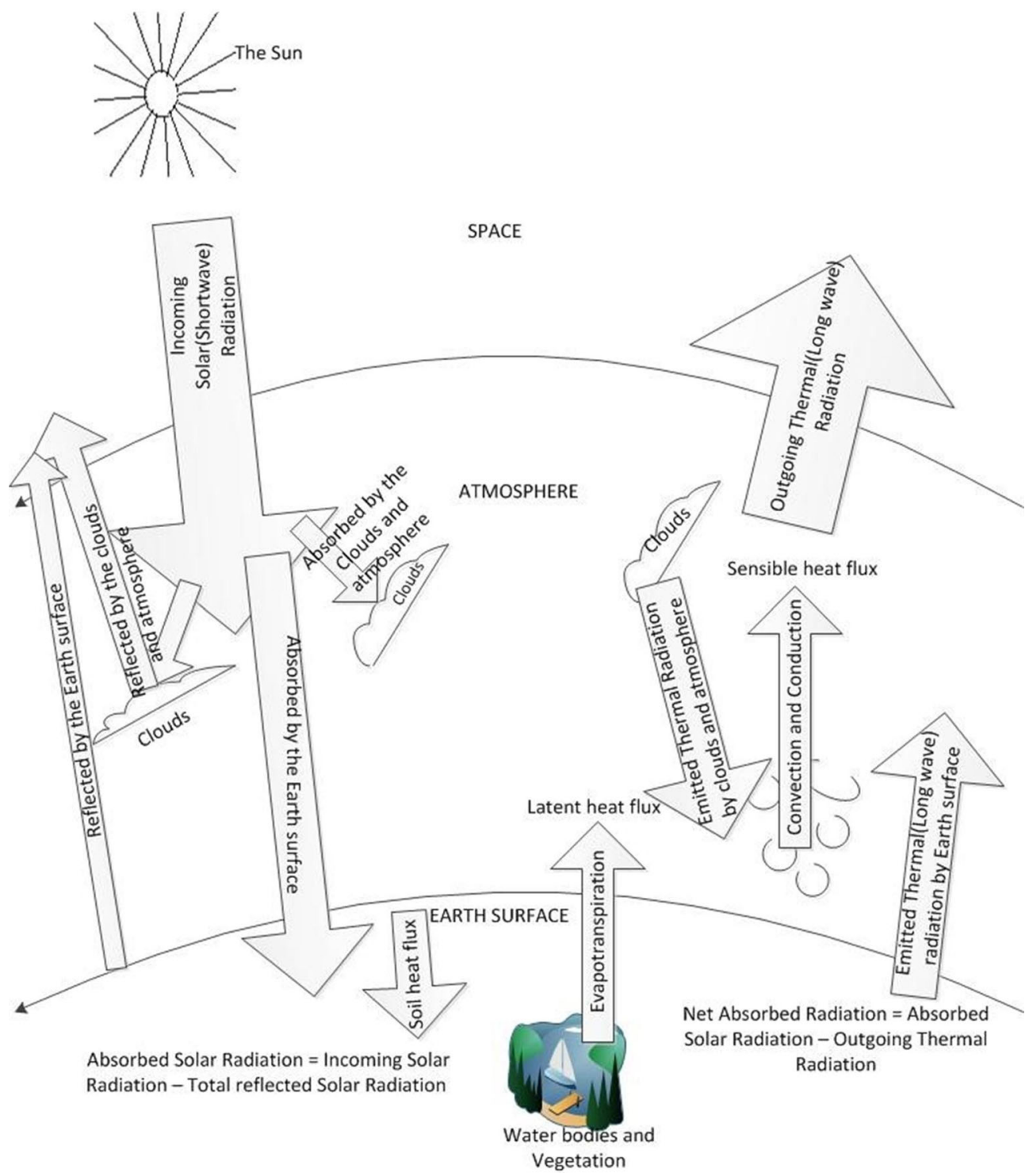

Figure 1. The conceptual diagram of the Earth's SEB phenomena among the space, atmosphere and the Earth's surface.

based on both the ground and satellite estimation techniques. The SEB has four main components as shown in equation (1), the net radiation $\left(R_{\mathrm{n}}\right)$ is the combined calculation of solar (shortwave) and thermal (longwave) radiation, the sensible $(H)$ and latent (LE) heat fluxes are the results of atmospheric turbulences and soil/ground heat flux $(G)$ which can be calculated as the function of net radiation, soil and vegetation characteristics (Bastiaanssen et al. 1998a,b). So, the estimation of net radiation using the solar and thermal radiations and estimation of any other heat flux using energy balance approach will have to go through the indirect estimation of all SEB components. As the energy balance is not closed (Foken 2008), therefore indirect estimation of a SEB component may lead to errors and uncertainties. Hence, the individual estimation of sensible heat flux $(H)$ and soil heat flux $(G)$ can be studied further.

This study explains the fundamental and advanced estimation techniques of SEB components in more concise words and equations when compared with other reviews. However, an important purpose of this paper is to provide an overall idea to a reader, who is not specialist in this field. The meanings of all used symbols in this study are indicated in table 1 for quick reference. Along with the main concepts, advantages, disadvantages and uncertainties, we make some recommendations to the readers/researchers, where one can apply these methods. This paper aims to review the recent development in the estimation methods and models of three basic components of the Earth's SEB such as solar radiation, thermal radiation and the 
Table 1. The used symbols and their respective meanings.

\begin{tabular}{|c|c|}
\hline Symbols & Meanings \\
\hline$\alpha$ & Surface albedo \\
\hline$\gamma$ & Psychrometric constant \\
\hline$\varepsilon$ & Atmospheric emissivity \\
\hline$\Delta$ & Slope of saturated vapour pressure \\
\hline$\Delta T$ & Vertical difference of temperature \\
\hline$\Delta q$ & Vertical difference of water vapour concentration \\
\hline$\Delta z$ & Vertical distance between two measurement points \\
\hline$\lambda$ & Latent heat of evaporation/vapourisation \\
\hline$\rho$ & Density of air \\
\hline$\rho_{\text {dry }}$ & Density of dry air \\
\hline$\rho_{v}$ & Density of water vapour \\
\hline$\dot{\rho}_{v}$ & Fluctuation in water vapour density \\
\hline$\rho_{\text {wet }}$ & Density of wet/moist air \\
\hline$\sigma$ & Stefan-Boltzmann constant \\
\hline$B$ & Bowen ratio \\
\hline$C_{n}^{2}$ & Refractive index fluctuation of air \\
\hline$C_{p}$ & Specific heat of air at constant pressure \\
\hline DEM & Digital elevation model \\
\hline $\mathrm{d} T$ & $\begin{array}{l}\text { Temperature difference between air and surface (temperature } \\
\text { gradient) }\end{array}$ \\
\hline$e$ & Actual vapour pressure \\
\hline$e_{\text {sat }}$ & Saturated vapour pressure \\
\hline$E_{\text {in }}$ & Received radiation at the pyrgeometer/sensor surface \\
\hline$E_{\mathrm{m}}$ & Measured radiation at the pyrgeometer/sensor surface \\
\hline$E_{\text {out }}$ & Emitted radiation at the pyrgeometer/sensor surface \\
\hline $\mathrm{EF}$ & Evaporative fraction \\
\hline $\mathrm{EF}_{\mathrm{r}}$ & Relative evaporative fraction \\
\hline ET & Evapotranspiration \\
\hline $\mathrm{ET}_{\mathrm{a}}$ & Actual evapotranspiration \\
\hline $\mathrm{ET}_{\text {dry }}$ & Evapotranspiration at dry reference pixel \\
\hline $\mathrm{ET}_{\mathrm{r}}$ & Reference evapotranspiration \\
\hline $\mathrm{ET}_{\text {wet }}$ & Evapotranspiration at wet reference pixel \\
\hline$f_{\mathrm{c}}$ & Fractional vegetation cover \\
\hline$G$ & Ground/soil heat flux \\
\hline$H$ & Sensible heat flux \\
\hline$H_{\mathrm{c}}$ & Canopy sensible heat flux \\
\hline$H_{\text {dry }}$ & Sensible heat flux at dry reference pixel \\
\hline$H_{\mathrm{s}}$ & Soil sensible heat flux \\
\hline$H_{\text {wet }}$ & Sensible heat flux at wet reference pixel \\
\hline$K_{H}$ & Coefficient of sensible heat transfer \\
\hline$K_{V}$ & Coefficient of latent heat transfer \\
\hline$L_{\mathrm{A}}$ & Leaf area index \\
\hline $\mathrm{LE}$ & Latent heat flux \\
\hline $\mathrm{LE}_{\text {dry }}$ & Latent heat flux at dry reference pixel \\
\hline $\mathrm{LE}_{\mathrm{wet}}$ & Latent heat flux at wet reference pixel \\
\hline NDVI & Normalised vegetation index \\
\hline$P$ & Atmospheric pressure \\
\hline$R^{1} \downarrow$ & Incoming longwave radiation \\
\hline$R^{1} \uparrow$ & Outgoing longwave radiation \\
\hline$R_{\mathrm{n}}$ & Net radiation \\
\hline$R_{\mathrm{n}}^{1}$ & Net longwave radiation \\
\hline$R_{\mathrm{n}}^{\mathrm{s}}$ & Net shortwave radiation \\
\hline$R^{\mathrm{s}} \downarrow$ & Incoming shortwave radiation \\
\hline
\end{tabular}


Table 1. (Continued.)

\begin{tabular}{ll}
\hline Symbols & \\
\hline$R^{\mathrm{s}} \uparrow$ & Outgoing shortwave radiation \\
$r_{\mathrm{ah}}$ & Aerodynamic resistance \\
$r_{\text {ah_c }}$ & Canopy aerodynamic resistance \\
$r_{\text {ah_dry }}$ & Aerodynamic resistance at dry reference pixel \\
$r_{\text {ah_wet }}$ & Aerodynamic resistance at wet reference pixel \\
$r_{\text {ah_s }}$ & Soil aerodynamic resistance \\
$S$ & Sensitivity/calibration factor of instrument \\
$T$ & Absolute temperature of pyrgeometer/sensor detector \\
$T$ & Fluctuation in air temperature \\
$T_{\mathrm{a}}$ & Air temperature \\
$T_{\mathrm{c}}$ & Canopy temperature \\
$T_{\mathrm{H}}$ & Maximum surface temperature in dry condition \\
$T_{\mathrm{LE}}$ & Minimum surface temperature in wet condition \\
$T_{\mathrm{rad}}$ & Directional radiometric surface temperature \\
$T_{\mathrm{S}}$ & Surface temperature/also used as soil temperature \\
$T_{\mathrm{s} \text { DEM }}$ & Surface temperature adjusted to a standard elevation per pixel of \\
$U^{\prime}$ & the satellite image \\
$V_{\mathrm{emf}}$ & Fluctuation in vertical wind speed \\
\hline & Output voltage of the pyrgeometer/sensor thermopile
\end{tabular}

ET, i.e., latent heat flux from satellite and ground measurements to achieve the present status and future directions in the study area.

\section{Solar (shortwave) radiation}

The solar radiation is the only significant energy source on the Earth that is transformed into various energy fluxes after entering into the atmosphere and Earth's surface. Basically, solar radiation has two acting parts: one is incoming (downward $R^{\mathrm{s}} \downarrow$ ) radiation on Earth's surface that depends on the atmospheric transmitivity, solar constant, solar altitude and incidence angle, and another part is outgoing (upward $R^{\mathrm{s}} \uparrow$ ) that is reflected back to space due to the combined effect of surface, clouds, aerosol, gases, etc. It is a measure of radiation received on a given area in a given time, usually indicated as the average irradiance in watts per square metre $\left(\mathrm{W} \mathrm{m}^{-2}\right)$ that engenders in visible (VIS) and near-infrared (NIR) spectra (wavelength of 300-4000 nm).

\subsection{Ground measurement of solar radiation}

The basic science of solar irradiance is the detection of the optical electromagnetic radiation that is converted into electric signals, which can be measured by conventional techniques. There are two types of instruments available for measuring solar radiation such as pyrheliometer for direct irradiance and pyranometer for both direct and diffuse irradiances (Paulescu et al. 2013). The pyrheliometer is a broadband instrument that measures the direct beam of solar radiation. The pyranometer is a type of actinometer for measuring solar radiation (direct and diffuse) incoming from a $2 \pi\left(360^{\circ}\right)$ solid angle on a planar surface as shown in figure 2 . These instruments are classified with respect to their quality by the International Standard ISO 9060/1990 that is also adopted by the World Meteorological Organization (WMO) (Guide to Meteorological Instruments and Methods of Observation, Seventh Edition 2008).

However, there are some worldwide and regional ground measurement networks for measuring the surface flux components as briefly described here. The WMO started the measurement of solar radiation from 1964 along with other components for surface radiation energy balance. The World Radiation Data Center (WRDC) is located at the Central Geophysical Observatory in St. Petersburg, Russia inside WMO that collects data from the large network with more than 1000 stations for monitoring solar radiation (Main Geophysical Observatory, World Radiation Data Center, St. Petersburg, Russia). The Baseline Surface Radiation Network (BSRN) (Ohmura et al. 1998) is a project under the umbrella of the World Climate Research Program (WCRP) (World Climate Research Programme n.d.) (n.d. stands for no date or year of publication, i.e., the citation is only 


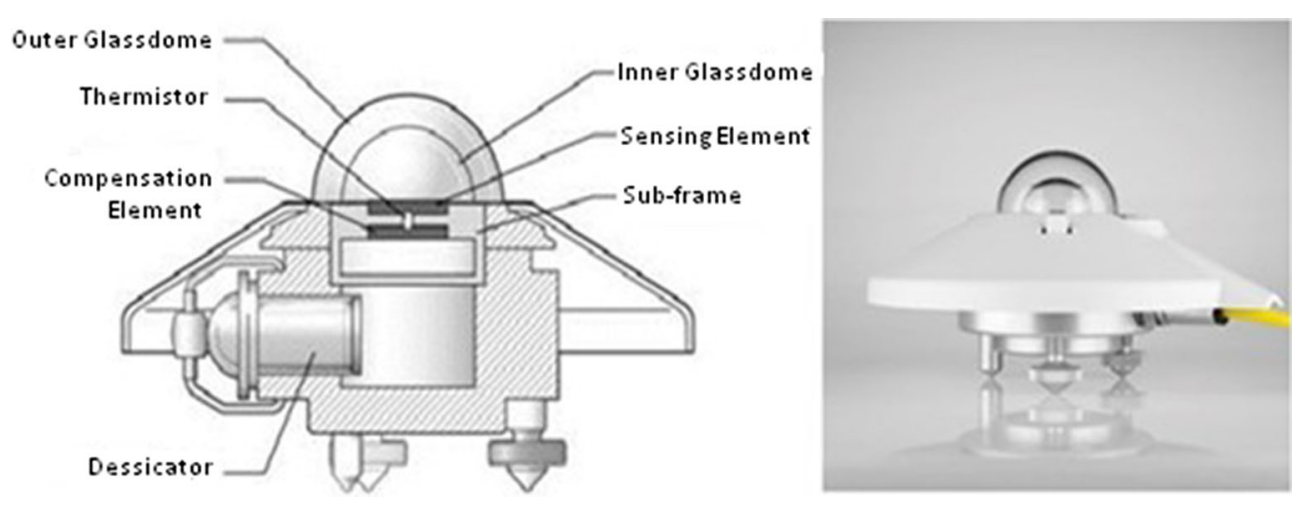

Figure 2. The schematic diagram (left) and photograph (right) of pyranometer (Solar Instruments/Atmospheric Science Instruments n.d.).

available on website/Internet) as a part of Global Energy and Water Cycle Exchange (GEWEX) (Global Energy and Water Cycle Exchange n.d.) for land surface radiation measurement with a small number of stations (currently 59 as of December 2016) covering a latitude range from $80^{\circ} \mathrm{N}$ to $90^{\circ} \mathrm{S}$ (Baseline surface radiation network n.d.). The Global Energy Balance Archive (GEBA) is a database established in 1985 at ETH Zurich for measuring the monthly means of surface energy fluxes (Gilgen and Ohmura 1999). The Surface Radiation Budget Network (SURFRAD) is a nation-wide network of US National Oceanic and Atmospheric Administration (NOAA) (Surface Radiation (SURFRAD) Network n.d.) to measure the surface radiation budgets over the United States since 1993 (Augustine et al. 2005). FLUXNET (Baldocchi et al. 2001 ) is a set of regional networks that coordinate regional and global analysis to measure the exchange of carbon dioxide $\left(\mathrm{CO}_{2}\right)$, water vapour and energy between terrestrial ecosystems and the atmosphere based on eddy-covariance method with 683 (as of April 2016) sites (FLUXNET A Global Network n.d.) over seven regions (AmeriFlux, CarboEurope, KoFlux, OzFlux, Fluxnet-Canada, AsiaFlux and ChinaFlux). Some other regional networks also exist and these networks have a set of stations to cover a desired area but the matter is that how much areas are covered and how these stations are distributed, i.e., the optimum distance between two stations. Cros and Wald (2003) showed that a station can cover an area of $\sim 30 \mathrm{~km}$. Most of the measuring projects are using the Kipp and Zonen or Eppley or Hukseflux standard instruments to ensure the quality data collection.

\subsection{Satellite estimates of solar radiation}

Satellite remote sensing techniques are the only effective way to estimate the components of land SEB at both regional and global scales in contrast to the limited ground-based estimations. There has been a firm advancement in estimating the Earth's radiation budget since the first meteorological satellite was launched in the 1960s. Basically, these types of satellites measure the radiation of different wavelengths in the electromagnetic spectrum, i.e., collect images of different spectrum such as VIS, NIR, thermal infrared (TIR) and microwave range as radiation is the form of energy that can be transmitted without any material medium. However, the general procedure of satellite estimates of the Earth's SEB components is outlined in figure 3, which shows that we still need some ground measurement. The meteorological and solar radiation data are used for deriving some models and the surface energy components for accuracy measurements. Researchers are following the above illustrated procedure for estimating the surface fluxes and trying to use less ground data for deriving their methods/models to achieve the high accuracy with respect to ground measurements.

\subsubsection{Satellite sensors}

Various broadband radiometric sensors are on board in multiple satellite spacecrafts - the Earth Radiation Budget (ERB) sensor on Nimbus-7 (Jacobowitz and Tighe 1984); the Earth Radiation Budget Experiment (ERBE) sensor on three satellites which are NOAA-F, NOAA-G and another one with $57^{\circ}$ inclination orbit which travels around the Earth once every 2 months (Barkstrom and 


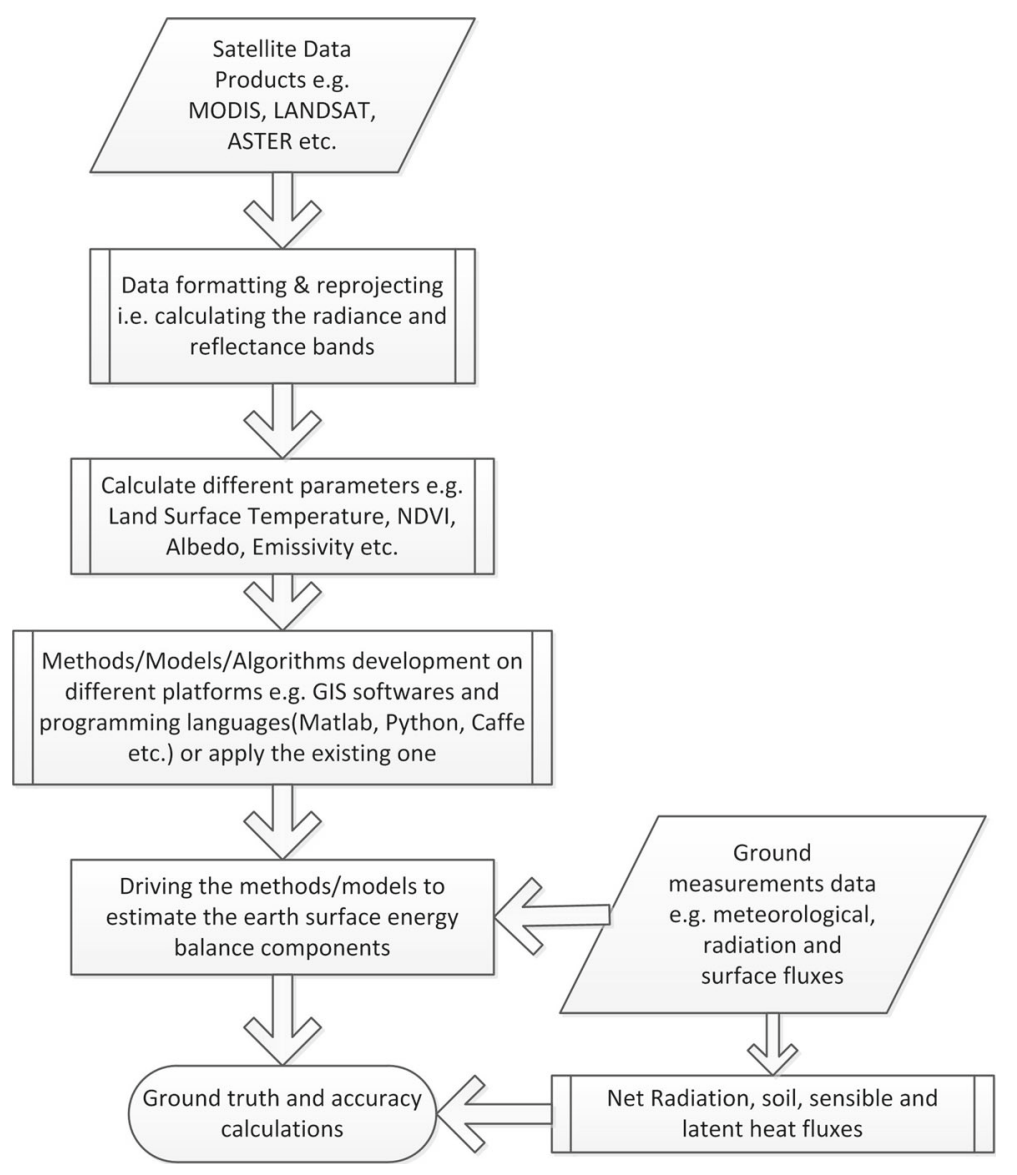

Figure 3. The flow chart of generalised estimation procedure of the Earth's SEB components from satellite measurements.

Smith 1986); the Clouds and the Earth's Radiant Energy System (CERES) (The Clouds and the Earth's Radiant Energy System n.d.) sensor which was 1st launched on Tropical Rainfall Measurement Mission (TRMM) in 1997 including European Space Agency's (EOS) Terra, Aqua and recently the Suomi National Polar Orbiting Partnership (S-NPP) (Soumi NPP n.d.); the Advanced Spaceborne Thermal Emission and Reflection Radiometer (ASTER) on Terra in 1999 (The Advanced Space-borne Thermal Emission and Reflection Radiometer n.d.) and the Geostationary Earth Radiation Budget (GERB) sensor on Meteosat8 and Meteosat-9 launched in 2002 and 2007, respectively (Harries et al. 2005). There are also some sensors to produce surface radiation on both geostationary and orbiting satellites such as the Spinning Enhanced Visible and Infrared Imager (SEVIRI) on Meteosat Second Generation (MSG) satellite (Schmetz et al. 2002); the Advanced Baseline Imager (ABI) sensor on Geostationary Operational Environmental Satellite (GOES) (The Geostationary Operational Environmental Satellite-Advanced Baseline Imager (ABI) n.d.) and
Moderate Resolution Imaging Spectro radiometer (MODIS) on Terra in 1999 and Aqua in 2002 (MODIS n.d.). In the case of data accumulation, the calibration of satellite instruments is mostly important but some missions did not have onboard calibration devices, which makes the data processing more complicated and another problem is the time gap like eight years between EREB and CERES. The meteorological satellites are able to collect the high temporal resolution (hourly) images over a large area, which are then further processed and compared with ground measurements to extract the desired information. It can derive the hourly irradiation most accurately at locations that are further $25 \mathrm{~km}$ away from a ground station (Zelenka et al. 1988).

\subsubsection{Estimation methods}

There are numerous methods for retrieving solar radiation from satellite signals. The development of these methods is still on going. At this stage, we can roughly classify these methods into three categories. First, the look-up-table (LUT) method 
is a data structure that is developed based on the radiative transfer process (Liang et al. 2006; Lu et al. 2010; Huang et al. 2011). This method is extensively used to achieve high accuracy even it has some drawbacks such as computationally not economical and used in limited channel data. Second, the parameterisation methods that estimate solar radiation by establishing a model, i.e., the process of developing parametric equations with several parameters such as cloud, aerosol, gas and other atmospheric and surface variables (Kim and Ramanathan 2008; Wang and Pinker 2009; Lichun et al. 2015). Sometimes it is hard to keep the temporal resolution high due to the changing tendencies of some input parameters (e.g., cloud parameters). Third, the statistical method which is developed based on the statistical process and artificial neural network (ANN) that directly link the satellite observed signals to estimate solar radiation at regional scale ( $\mathrm{Lu}$ et al. 2011; Hena et al. 2013). The most common disadvantage of these methods is the lack of generalisation. However, many researchers utilised the combination of the above stated methods (Rigollier et al. 2004; Kawai and Kawamura 2005; Yeom and Han 2010; Wang et al. 2014), which is known as the hybrid method. The summary of the above stated methods is listed in table 2 .

\section{Thermal (longwave) radiation}

Longwave radiation is the electromagnetic radiation that is being emitted from the Earth's surface and atmosphere as infrared $(4-100 \mu \mathrm{m})$ at low energy in the form of thermal radiation to space. It is measured in $\mathrm{W} \mathrm{m}^{-2}$ and mathematically expressed as in equation (4). The longwave radiation also has two parts: one is outgoing longwave radiation (the dominating part) which depends on the land surface characteristics such as surface temperature and emissivity and another is the incoming longwave radiation that depends on the cloud cover and humidity, i.e., the sky temperature and sky emissivity. The incoming solar radiation and outgoing longwave radiation are the key components of radiation balance. These are extremely important to develop any land surface and climate model because the Earth's surface and atmosphere gain energy by absorbing solar (shortwave) radiation, which is known as radiative heating, and lose energy by emitting thermal (longwave) radiation to balance the absorption of

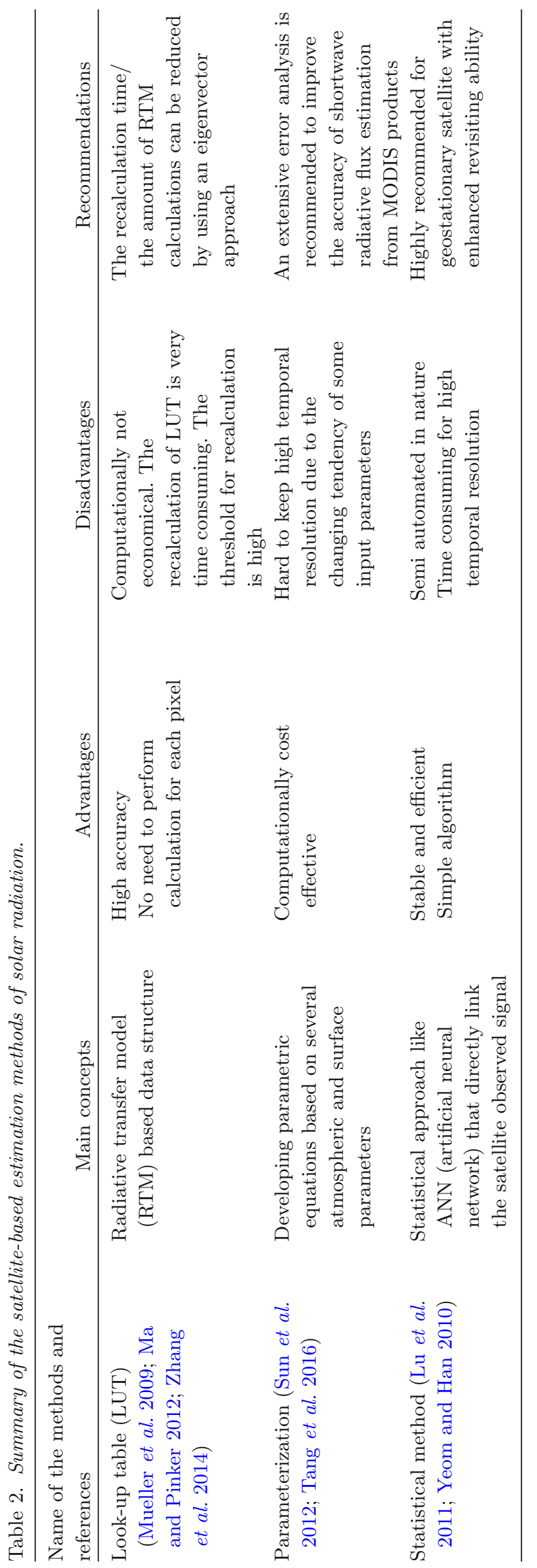


solar radiation, also known as radiative cooling (Kiehl and Trenberth 1997). The resultant of these two components is the net radiation that determines the ultimate heating or cooling of global system.

\subsection{Ground measurement of thermal radiation}

At surface, the longwave radiation is mainly measured by pyrgeometer. It is an electronic device that measures near surface infrared radiation spectrum according to the following mathematical relationships (Pyrgeometer n.d.):

$$
E_{\mathrm{m}}=E_{\text {in }}-E_{\text {out }},
$$

where $E_{\mathrm{m}}$ is the measured radiation at the pyrgeometer sensor surface in $\mathrm{W} \mathrm{m}^{-2}, E_{\text {in }}$ is the longwave radiation received from the atmosphere and $E_{\text {out }}$ is the longwave emitted by the sensor surface. Now, the generated radiation at the instrument sensor surface can be calculated as

$$
\begin{aligned}
E_{\mathrm{m}} & =\frac{V_{\mathrm{emf}}}{S}, \\
E_{\mathrm{out}} & =\sigma T^{4},
\end{aligned}
$$

where $V_{\text {emf }}$ is the output voltage of the pyrgeometer thermopile in volts $(\mathrm{V}), S$ is the sensitivity/calibration factor of the instrument in $\mathrm{V} \mathrm{W}^{-1} \mathrm{~m}^{-2}, \sigma$ is the Stefan-Boltzmann constant in $\mathrm{W} \mathrm{m}^{-2} \mathrm{~K}^{-4}$ and $T$ is the absolute temperature of pyrgeometer detector in K. Therefore, the longwave radiation can be calculated as

$$
E_{\text {in }}=\frac{V_{\mathrm{emf}}}{S}+\sigma T^{4} .
$$

A schematic diagram and photograph of pyrgeometer is shown in figure 4. However, the ground-based measurement networks as described in previous section such as BSRN, WRC, GEBA, FLUXNET, SURFRAD, etc. also collect the longwave radiation data over their coverage regions. The accuracy of longwave radiation measurement was set to $30 \mathrm{~W} \mathrm{~m}^{-2}$ as per BSRN standard, recent measured data are more faithful of $\pm 5 \mathrm{~W} \mathrm{~m}^{-2}(1.5 \%)$ and the quality check performed by updated BSRN tools (Long and Dutton 2002; Schmithüsen et al. 2012).

\subsection{Satellite estimates of thermal radiation}

Due to the limited coverage and maintenance complexity of ground measurements in large scale, the satellite retrieval of longwave radiation is very important for analysing the Earth's climate system. The measurement of longwave radiation flux is affected by the processes of scatterings, absorptions and emissions from clouds, aerosols, gases and the surface. The researchers are developing various algorithms based on different types of methods, which can be categorised roughly into three.

The first type is known as the empirical method based on the empirical functions using satellitederived meteorological parameters such as surface temperature and water vapour burden (Ellingson et al. 1983; Wang and Liang 2009). This method with simple algorithms is sensitive to errors but widely used in numerous applications. The second type is the radiative transfer method (RTM; Schmetz 1989; Vázquez-Navarro et al. 2013) that calculates the radiation quantities using the atmosphere temperature and water vapour profiles, it can directly measure the downward longwave radiation using atmospheric profiles and the upward longwave radiation using land surface profiles as it has the strong validity of physics. The third type is known as the hybrid method (Wang and
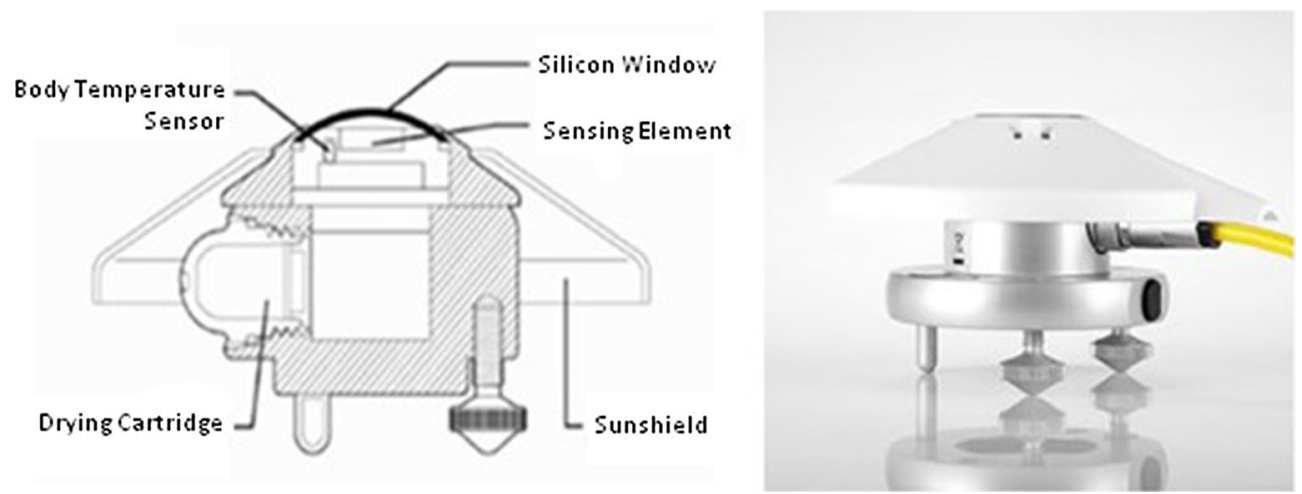

Figure 4. The schematic diagram (left) and photograph (right) of pyrgeometer (Solar Instruments/Atmospheric Science Instruments n.d.). 
Liang 2010; Jiao et al. 2015) that is developed based on the combination of radiative transfer simulation and the statistical approaches such as ANN. The hybrid method indicates that there is a good generalisation and also the good accuracy. The summary of the above indicated methods is provided in table 3 .

\section{ET (latent heat flux)}

ET is the vital component of the Earth SEB that is the collective value of evaporation from water bodies and the transpiration from vegetation and/or any other moisture containing living tissues, i.e., the processes of losing water from the Earth's surface to the atmosphere by both the evaporation and transpiration. This component is characterised by the latent heat flux of the Earth's surface as mathematically expressed in equation (6). This process cools the Earth's surface and moistens the atmosphere near surface which is why the estimation of ET is crucial for developing climatic, hydrological, bio-geophysical and ecological models to predict the weather and climate or climate change. A lot of efforts have been made for the accurate estimation procedure of ET as described in this section.

\subsection{Ground measurement of ET}

The potential ground measurement of ET has not been well observed with the common in-situ instruments and methods. Basically, micrometeorological measurement-based methods are vastly implemented to estimate ET (the latent heat flux) such as Bowen ratio energy balance (BREB), eddy covariance (EC) and Penman-Monteith (PM) method (Gavilán and Berengena 2007; Shi et al. 2015). ET can also be estimated based on weighing lysimeter (Gebler et al. 2015), providing the only direct measurement of water flux from vegetated area, i.e., the lysimeter water balance.

The BREB methodology is developed based on the SEB equation. The Bowen ratio (Bowen 1926) is defined as the ratio of the sensible heat flux $(H)$ to the latent heat flux (LE) as expressed in the following equation:

$$
B=\frac{H}{\mathrm{LE}}=\frac{K_{H} \rho C_{p} \frac{\Delta T}{\Delta Z}}{K_{V} \lambda \frac{\Delta q}{\Delta Z}},
$$

where $K_{H}$ and $K_{V}$ are the coefficient of sensible and latent heat transfer, $\rho$ is the air density, $C_{p}$ is the air specific heat, $\lambda$ is the latent heat

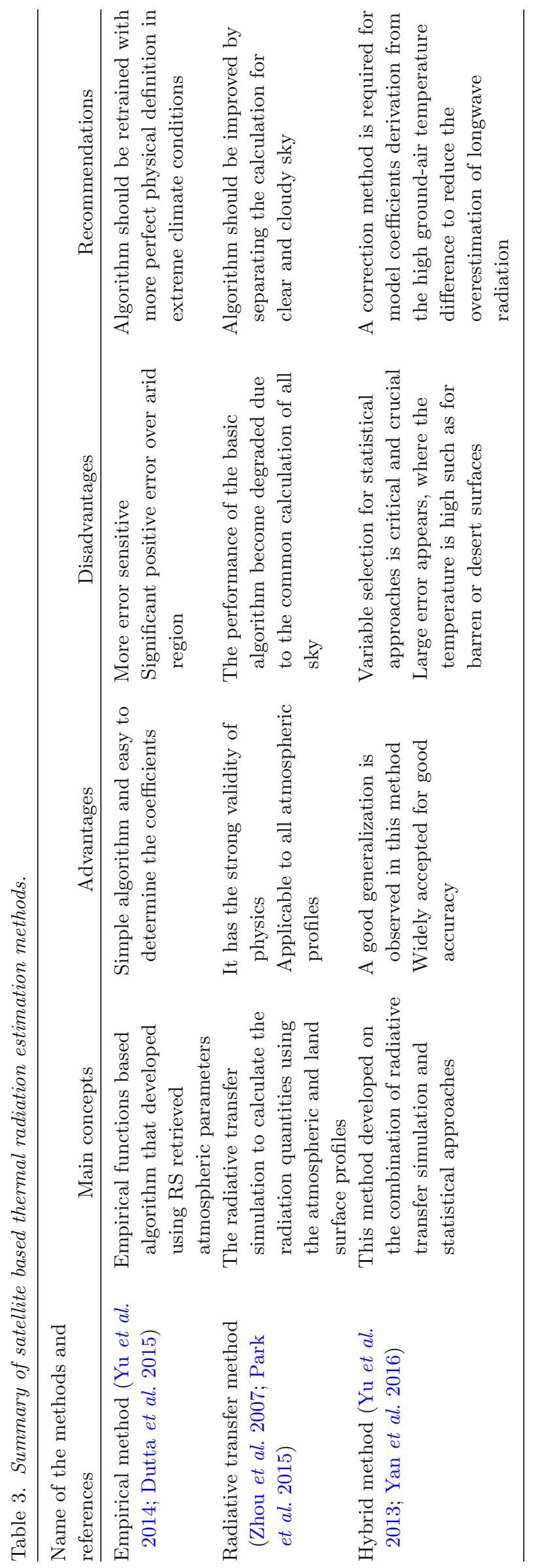




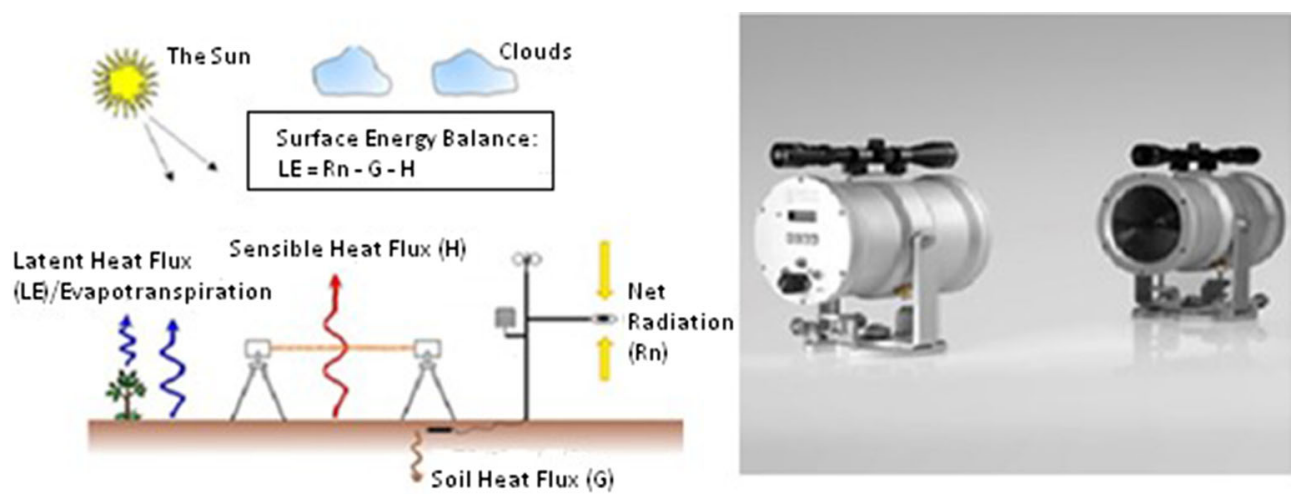

Figure 5. The operational diagram (left) and photograph (right) of the large aperture scintillometer (LAS) MkII ET System (Solar Instruments/Atmospheric Science Instruments n.d.).

of vapourisation, $\Delta T$ and $\Delta q$ are the vertical differences of temperature and water vapour concentration and $\Delta Z$ is the vertical distance between the two measurement points. Now equation (6) can be rewritten as

$$
\mathrm{LE}=\frac{R_{\mathrm{n}}-G}{1+B}
$$

In equation (12), if we have known $B$ for a certain system then LE can be calculated from the measured net radiation $\left(R_{\mathrm{n}}\right)$ and soil heat flux $(G)$.

The EC method (Pauwels and Samson 2006; Ha et al. 2015) estimates $H$ and LE directly from the fluctuations of wind speed, temperature and water vapour. Observing the covariance between water vapour density and wind speed, we can calculate the latent heat flux as

$$
\mathrm{LE}=\lambda \overline{\rho_{v} \dot{U}^{\prime}},
$$

where $\lambda$ is the latent heat of vapour, $\rho_{v}$ is the fluctuation in water vapour density $\left(\mathrm{kg} \mathrm{m}^{-3}\right), U^{\prime}$ is the fluctuation in vertical wind speed $\left(\mathrm{m} \mathrm{s}^{-1}\right)$ and the overbar stands to indicate the average operation. Similarly, the sensible heat flux can be calculated as

$$
H=\rho C_{p} \bar{T} \bar{U},
$$

where $\rho$ is the density of the surrounding air and $T$ is the fluctuation in air temperature $\left({ }^{\circ} \mathrm{C}\right)$.

In recent years, the use of scintillometer has become popular for its large area coverage and good performance (Nieveen and Green 1998; Meijninger 2003; Ward and Evans 2015). Scintillometer is an electronic device that measures the sensible heat flux $(H)$ of the surface and then calculates the latent heat flux (LE) using other climatic parameters (net radiation and soil heat flux) based on the SEB. The basic principle is that it measures the turbulent intensity of the refractive index fluctuations $\left(C_{\mathrm{n}}^{2}\right)$ of air between a collimated light source (transmitter) and a detector (receiver). The transmitter sends a beam of light (electromagnetic radiation) at a known wavelength over a known distance of one to several kilometres and at the end of the path the receiver collects the travelled radiation and analyses the fluctuations of the radiation intensity to find out the turbulent heat fluxes. An operational diagram and photograph of large aperture scintillometer (LAS) is shown in figure 5. The estimated result of ET using this method shows a good agreement with the remote sensing-based estimation. Samain et al. (2012) presented the ET rates calculated per 10 -day periods. It showed a good agreement between the remote sensing-based estimation and LAS-derived results with difference from $3.5 \%$ to $12.6 \%$.

\subsection{Satellite estimates of ET}

Nowadays, satellite retrieval of ET has become a widespread area of interest to researchers for its highest cost effectiveness and large area coverage with revisiting capability as well as the reasonably good accuracy. The satellite-based estimation of ET started roughly from 1980 and is still developing based on various approaches and methods. It is hard to say which method or approach is the best because every aspect of these approaches/methods has its own merits and demerits. There are variety of models and methods for ET retrieval from satellite data such as the SEB-based methods (Kustas 1990), surface temperature vegetation indices (Ts-VI)-based methods (Tang et al. 2009), the Penman-Monteith (PM) method (Zhang et al. 2009), Priestley-Taylor (PT) method (Fisher et al. 
2008), empirical method (Wang et al. 2007), water balance method (Wan et al. 2015) and other methods (Ryu et al. 2011; Wang and Bras 2011). These methods are further simplified and modified to improve their performance. The significant advantage of SEB methods is that these are using the energy balance approach, which can quantify surface fluxes and their water-use dynamics without reference to the source of water information as opposed to other models such as water-balance model, which requires detailed information of water sources. However, this paper focuses on various SEB-based methods and models.

\subsubsection{Surface energy balance index (SEBI)}

The SEBI model is based on the crop water stress index (CWSI), by scaling up the observed temperature in the maximum $(\max )$ temperature (dry condition) and the minimum (min) temperature (wet condition) (Jackson et al. 1981), which is the fundamental concept for all the SEB models. The observed max and min surface temperatures are interpolated to calculate the relative evaporative fraction $(\mathrm{EF})$ then for a particular surface albedo and roughness, the pixelwise SEBI computes the regional ET from pixelwise max and min surface temperature redefined CWSI and relative EF. Due to the complexity in the determination of the max and min surface temperatures and poor accuracy of SEBI, it was further developed with a simplified form named simplified-SEBI (S-SEBI) (Roerink et al. 2000). Here, a reflectance (albedo)dependent max and min surface temperatures are pointed out to determine the dry and wet conditions for partitioning the available energy into sensible and latent heat fluxes. The ET is calculated in terms of EF, which can be defined as the ratio of ET/latent heat flux (LE) to the available energy $\left(R_{\mathrm{n}}-G\right)$. Under the dry and wet conditions, it can be formulated by interpolating the albedodependent surface temperatures as

$$
\mathrm{EF}=\frac{T_{\mathrm{H}}-T_{\mathrm{s}}}{T_{\mathrm{H}}-T_{\mathrm{LE}}}
$$

where $T_{\mathrm{H}}$ is the max surface temperature at dry conditions and represents the max sensible heat flux and min latent heat flux, $T_{\mathrm{LE}}$ is the min surface temperature at wet conditions and represents the max latent heat flux and min sensible heat flux and $T_{\mathrm{s}}$ is the surface temperature.

\subsubsection{Surface energy balance system (SEBS)}

The SEBS was developed by Prof $\mathrm{Dr} \mathrm{Su}$ in the Netherlands in 2002 to estimate the actual ET and other land surface heat fluxes in terms of atmospheric turbulent fluxes and EF from remote sensing (RS)-based data and some meteorological measurements (Su 2002; Su et al. 2003). Basically, it is the modified form of SEBI; here, the assumptions are: the latent heat flux is zero at the dry limit, i.e., the sensible heat flux $\left(H_{\mathrm{dry}}\right)$ is maximum (the available energy, $R_{\mathrm{n}}-G$ ); on other hand, at wet limit, $H_{\text {wet }}$ reaches at its minimum value as expressed:

$$
\begin{aligned}
H_{\mathrm{dry}} & =R_{n}-G \\
H_{\mathrm{wet}} & =\frac{\left(R_{\mathrm{n}}-G\right) \gamma}{\gamma+\Delta}-\frac{\rho C_{\mathrm{p}}\left(e_{\mathrm{sat}}-e\right)}{r_{a h}(\gamma+\Delta)}, \\
\gamma & =\frac{C_{\mathrm{p}} P}{0.622 \lambda},
\end{aligned}
$$

where $\gamma$ is the psychrometric constant $\left(\mathrm{k} \mathrm{Pa}^{\circ} \mathrm{C}^{-1}\right)$, $P$ is the atmospheric pressure $(\mathrm{Pa}), \Delta$ is the slope of saturated vapour pressure as a function of $T_{a}$ in $\mathrm{k} \mathrm{Pa}{ }^{\circ} \mathrm{C}^{-1}$, $e$ and $e_{\mathrm{sat}}$ are the actual and saturated vapour pressures, and $r_{\mathrm{ah}}$ is dependent on the Obukhov length which in turn is a function of the friction velocity and sensible heat flux. Now the relative evaporative fraction $\left(\mathrm{EF}_{\mathrm{r}}\right)$ and $\mathrm{EF}$ can be expressed as

$$
\begin{aligned}
\mathrm{EF}_{\mathrm{r}} & =\frac{H_{\mathrm{dry}}-H}{H_{\mathrm{dry}}-H_{\mathrm{wet}}}, \\
\mathrm{EF} & =\frac{\mathrm{EF}_{\mathrm{r}} * \mathrm{LE}_{\mathrm{wet}}}{R_{\mathrm{n}}-G} .
\end{aligned}
$$

Here, to calculate the heat fluxes a distinction is made between the planetary boundary layer $(\mathrm{PBL}) /$ atmospheric boundary layer $(\mathrm{ABL})$ and the atmospheric surface layer (ASL) to take the ABL height as a reference of potential air temperature. In SEBS, the parameters are derived from RS data and ground (meteorological and radiation) data are used as inputs to estimate the sensible heat flux and EF as well as the other components.

\subsubsection{Surface energy balance algorithm for land (SEBAL)}

The SEBAL was developed by Prof. Bastiaanssen in the Netherlands in 1998, which is onelayer image processing model (Bastiaanssen et al. 
1998a, b). It estimates latent heat flux, i.e., ET as a residual of SEB and other land surface fluxes at both local and regional scales with minimum ground-based meteorological data. Basically, this model is a moderate approach based on both the empirical relationship and physical parameterisation scheme. Here, we need to collect the satellite imagery data of VIS, NIR, TIR spectra and also the land surface temperature $\left(T_{\mathrm{S}}\right)$, normalised vegetation index (NDVI) and albedo maps. The latent heat flux (LE) is estimated according to energy balance equation (6), where the net radiation $\left(R_{\mathrm{n}}\right)$ is computed from the balance of solar (shortwave) and thermal (longwave) radiation as indicated in equation (2), the soil heat flux $(G)$ is calculated by the proposed equation of Bastiaanssen (2000), which is applicable to all categories of vegetation cover and land. The sensible heat flux $(H)$ is computed according to equation (5), where SEBAL considers a linear relationship between the near surface-air temperature difference $(\mathrm{d} T)$ and the radiometric surface temperature $\left(T_{\mathrm{s}}\right)$ assuming the meteorological and surface conditions are homogeneous as expressed:

$$
\mathrm{d} T=c T_{\mathrm{s}}+d,
$$

where ' $c$ ' and ' $d$ ' are the empirical parameters obtained from the extreme evaporative condition, i.e., the 'anchor' pixel (Bastiaanssen 1995) for a given satellite image. The user can assign the dry/hot pixel and the wet/cold pixel to calculate $\mathrm{d} T$ on both conditions as

$$
\begin{aligned}
& \mathrm{d} T_{\mathrm{dry}}=\frac{H_{\mathrm{dry}} * r_{\mathrm{ah} \_\mathrm{dry}}}{\rho_{\mathrm{dry}} * C_{p}}, \\
& \mathrm{~d} T_{\text {wet }}=\frac{H_{\mathrm{wet}} * r_{\mathrm{ah} \_ \text {wet }}}{\rho_{\mathrm{wet}} * C_{p}} .
\end{aligned}
$$

where $r_{\text {ah_dry }}$ and $r_{\text {ah_wet }}$ are the aerodynamic resistances at dry and wet conditions, respectively. In equation (22), the value of sensible heat flux is assumed to be maximum as $H_{\text {dry }}=R_{\mathrm{n}}-G$ (maximum available energy) at dry pixel (taken from a pixel that located in an area that shows high surface temperature). In equation (23), the value of sensible heat flux $H_{\text {wet }}$ is assumed to be zero at wet pixel (generally taken from a pixel located in deep water/water body), i.e., $\mathrm{d} T_{\text {wet }}=0$. After determining the value of $\mathrm{d} T$ at both wet and dry pixels, the values of ' $c$ ' and ' $d$ ' in equation (21) can be easily estimated. By using the values of ' $c$ ', ' $d$ ' and respective surface temperature $\left(T_{\mathrm{s}}\right)$ of each pixel, the air-surface temperature difference $(\mathrm{d} T)$ at every pixel is calculated using equation (21). Finally, the value of sensible heat flux $(H)$ for each pixel is estimated iteratively with aerodynamic resistance corrected for stability using equation (5).

This method has been applied for ET estimation at both field and catchment scale in more than 30 countries such as Spain, Turkey, Egypt, India, Srilanka, China, USA, etc. over the world with an average accuracy of $85 \%$ (daily) and $95 \%$ (seasonal) at field scale (Bastiaanssen et al. 2010).

\subsubsection{Mapping evapotranspiration at high resolution with internalised calibration (METRIC)}

The METRIC is also an image processing tool (Allen et al. 2007) that is extended from SEBAL. The METRIC considers the slope aspect as $T_{\mathrm{s}}$ which relapses to $T_{\mathrm{S}}$ DEM (the surface temperature adjusted to a standard elevation per pixel of the satellite image) through a common arbitrary datum, based on the image-specific lapse rate. This method uses the ASCE (American Society for Civil Engineers) standardised reference evapotranspiration $\left(\mathrm{ET}_{\mathrm{r}}\right)$, which is calculated using the ASCE Penman-Monteith equation for alfalfa (about 0.5 $\mathrm{m}$ taller, rougher agricultural crop) field (ASCEEWRI 2005). Here, the calibration via reference $\mathrm{ET}$ is done by choosing the dry pixel as $\mathrm{ET}_{\text {dry }}=0$ and the wet pixel as $\mathrm{ET}_{\text {wet }}=1.05 \mathrm{ET}_{\mathrm{r}}$. However, this algorithm still suffers from the subjective specification of extreme pixels, i.e., dry and wet pixel selection.

\subsubsection{Two-source model (TSM)}

The TSM is also known as dual source model that was proposed by Norman et al. (1995) to improve the ET estimation accuracy from RS data (Sanchez et al. 2007). The basic concept of this model is to divide the composite radiometric temperature into two sources: one is soil and another is vegetative canopy, and to compute the sensible heat flux as the sum of canopy sensible heat flux $\left(H_{\mathrm{c}}\right)$ and soil sensible heat flux $\left(H_{\mathrm{s}}\right)$ is expressed as

$$
\begin{aligned}
& H=H_{\mathrm{c}}+H_{\mathrm{s}}, \\
& H_{\mathrm{c}}=\rho_{\text {air }} C_{\mathrm{p}} \frac{T_{\mathrm{c}}-T_{\mathrm{a}}}{r_{\mathrm{ah} \_\mathrm{c}}}, \\
& H_{\mathrm{s}}=\rho_{\text {air }} C_{\mathrm{p}} \frac{T_{\mathrm{s}}-T_{\mathrm{a}}}{r_{\text {ah_s }}},
\end{aligned}
$$


where $T_{\mathrm{c}}$ and $T_{\mathrm{s}}$ are the canopy and soil temperatures, respectively, $T_{\mathrm{a}}$ is the air temperature, and $r_{\text {ah_c }}$ and $r_{\text {ah_s }}$ are canopy and soil aerodynamic resistances, respectively. Here, $T_{\mathrm{c}}$ and $T_{\mathrm{s}}$ are related to the directional radiometric surface temperature $T_{\text {rad }}$ as

$$
\begin{aligned}
T_{\mathrm{rad}} & =\left[f_{\mathrm{c}} \cdot T_{\mathrm{c}}^{4}+\left(1-f_{\mathrm{c}}\right)^{4}\right]^{1 / 4}, \\
f_{\mathrm{c}} & =1-\exp \left(\frac{-0.5 \cdot \Omega \cdot L_{\mathrm{A}}}{\cos \theta}\right),
\end{aligned}
$$

where $f_{\mathrm{c}}$ is the fractional vegetation cover, $\Omega$ is a factor that indicates the degree to which the vegetation is clumped (Kustas and Norman 1999), $L_{\mathrm{A}}$ is the leaf area index and $\theta$ is the viewing angle of the radiometer. This model experiences some uncertainties in determining the initial and corrected value of the $\mathrm{PT}$ coefficients as it utilises the PT parameterisation scheme for energy partitioning (Yang et al. 2015).

However, there are also some other methods and model for mapping regional and local ET such as recently the NP (non-parametric) approach (Liu et al. 2012; Pan et al. 2016) has been proposed by few researchers, where the net radiation, surface air temperature, land surface temperature and soil heat flux as the inputs without the need of parameterising resistance. After reviewing the detailed literature related to the estimation techniques of ET fluxes, we make a summarisation as listed in table 4 .

\section{Errors and uncertainties associated with satellite estimations}

Several types of errors and uncertainties are found in satellite estimation of SEB components due to various problems and limitations in estimation methods and models, as well as the uneven characteristics of the atmosphere and Earth's surface. Some important sources of uncertainties and possible ways to reduce them are outlined here.

(1) Errors associated with surface temperature retrieved from satellite measurement: In the case of satellite estimation, most of the methods are using TIR radiation data to derive surface temperature. The atmospheric correction and surface emissivity affect the derivation of surface temperature; hence, the uncertainty is associated with the satellite measurement.
The surface temperature problem can be corrected using two methods, namely, direct and indirect methods, where the direct method uses the combination of atmospheric sounding and radiative transfer model but the indirect methods only use the satellite observations. The along track scanning radiometer (ATSR) observation can improve the estimation by performing the two nearly simultaneous measurements of brightness temperature from two different view angles. The consideration of both the directional radiometric surface temperature and emissivity on high spectral resolution (Norman et al. 1995) can reduce the uncertainty to some limit.

(2) Uncertainties due to coverage problem of satellite data: Different spatial and temporal scale SEB components are needed for several relevant departments at global and local scales. The simultaneous acquiring of high spatial and temporal resolution imagery is very hard because the satellites with high spatial coverage possess lower temporal frequency and vice versa. Also, the cloud covers obscure entire or parts of scene in an image, making it nearly impossible to obtain continuous coverage of an area. Hence, the spatio-temporal coverage problem may render the satellite estimation method impractical in relevant applications. There are some gap filling procedures (Anderson et al. 2007) and coupling models (Renzullo et al. 2008) to resolve this issue.

(3) Uncertainties in net radiation estimation: Net radiation is the key parameter of SEB, which quantifies the available energy $\left(R_{\mathrm{n}}-G\right)$. However, the net radiation estimation may lead to errors due to the ignorance of diurnal variation and phase difference between the diurnal cycles of each individual component (short and longwaves). In most of the SEB methods, total $R_{\mathrm{n}}$ flux is considered without the relative functions of direct and diffuse radiation. It is necessary to consider the effects of diffuse radiation than only direct radiation (Roderick et al. 2001).

(4) Uncertainties due to surface heterogeneity: The satellite measurement of some land surface variables such as temperature, aerodynamic resistance, leaf area index, fractional vegetation coverage, plant height, etc. are highly sensitive to surface types. The observational angular effect is prominent over homogeneous 


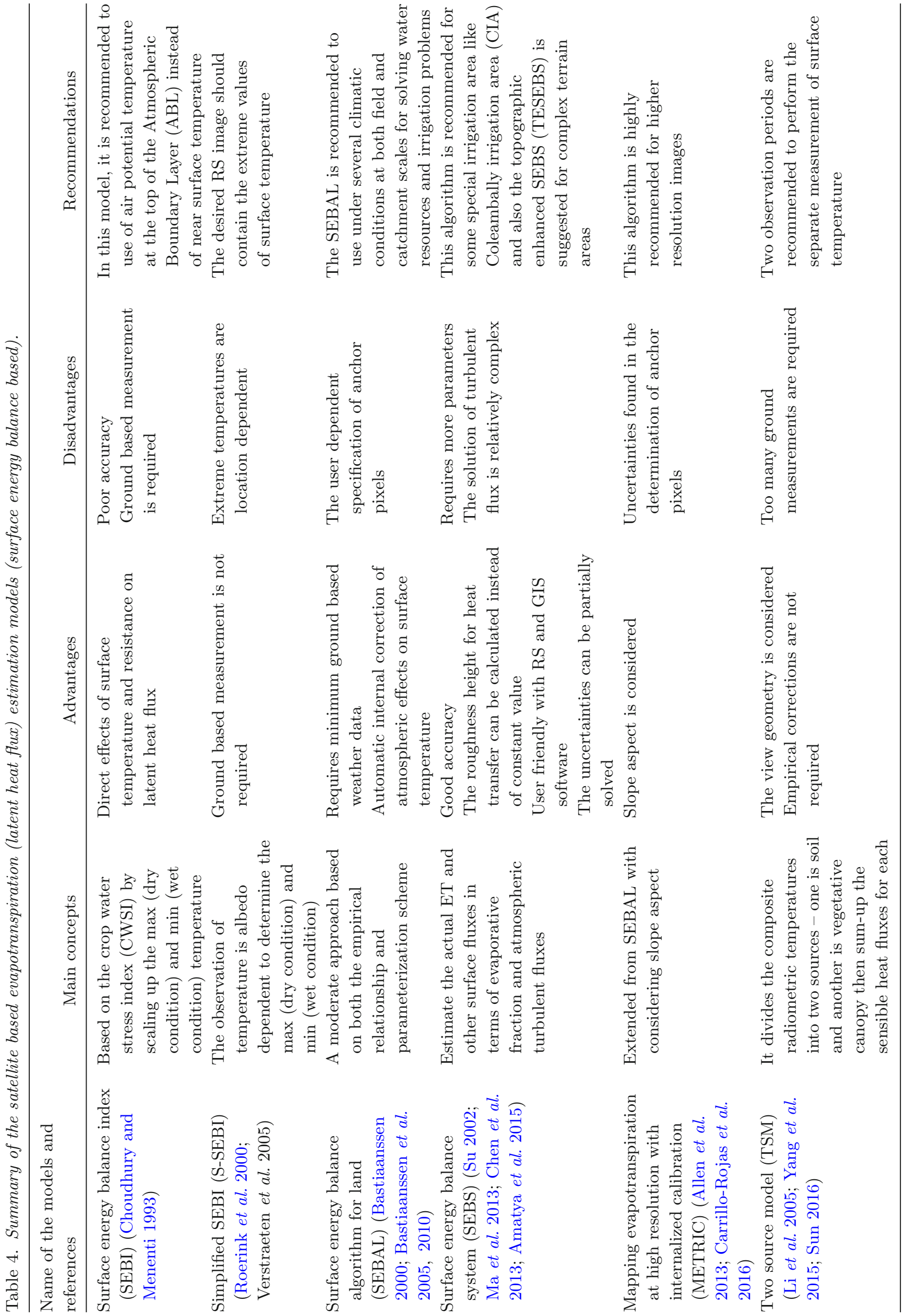


and dense vegetated surfaces but troublesome over heterogeneous surfaces (Carlson et al. 1994; Norman et al. 1995).

(5) Inconsistency in satellite estimation models: Different models are useful for different land surface types and meteorological conditions. Till date, there is no universal model, which could be used throughout the world. So, we need the modifications/improvements of the model to estimate SEB components at global scale, which leads to uncertainties.

(6) Insufficient near surface meteorological and flux data: Most of the satellite-based estimation models need the near surface meteorological data. Basically, the data from meteorological stations are obtained at a satellite pixel by spatial interpolation techniques. Different study regions have different climatic and terrain conditions with sparse/irregular meteorological and surface flux measurement stations. Therefore, the accuracy of the interpolation methods should be improved, as well as the ground-based meteorological and flux measurement networks also need further development.

(7) Night-time transpiration and early morning dew: If night-time transpiration occurs over a highly vegetated surface and this may be a significant error source in satellite estimation due to the nocturnal vapour pressure difference and wind speed (Dawson et al. 2007). Early morning dew over well-irrigated vegetation surface may affect the satellite measured radiant temperature (Pinter 1986). Hence, we should think about these issues before obtaining the satellite imagery.

In addition to the above-mentioned issues, other uncertainties in satellite measurements such as limitations of empirical vegetation index models, spatio-temporal scaling effects, lack of SEB components at satellite pixel for truth validation, etc. have been discussed in the literature (Wang et al. 2007; Kalma et al. 2008; Li et al. 2009).

\section{Recommendations}

In this study, we have discussed the advancements, limitations and uncertainties associated with different ground and satellite-based estimation methods and models and also provided some recommendations to researchers so that they can use these methods more specifically. The summarised recommendations, as indicated in tables $2-4$, can be explained in brief as follows to specify the key points for suitable applications of the respective methods and models:

(1) Recommendations on solar radiation estimation methods: Estimation of solar radiation at a large scale has many uses in the Earth system and photovoltaic power system applications. There are three categories of methods to estimate solar radiation. In the LUT method, a large number of radiative transfer model (RTM) calculations $\left(10^{5}-10^{7}\right)$ are required if specified scientific approaches are not applied (Mueller et al. 2009), where eigenvector approach is useful to reduce the RTM calculations by several orders. So, the use of a scientific approach such as eigenvector approach is recommended for the RTM-based methods. The parametrisation scheme is implemented with MODIS data product needs for an extensive error analysis to find out the major error sources of the model (Wang and Pinker 2009). Hence, an extensive error analysis is needed for parameterisation scheme with moderate resolution images. The geostationary satellite with high temporal frequency such as multi-functional transport satellite (MTSAT) is more suitable for continuous estimation of solar radiation using the statistical method ( $\mathrm{Lu}$ et al. 2011). For continuous estimation of solar radiation, the ANN-based statistical approaches are recommended using time-series images.

(2) Recommendations on thermal radiation estimation methods: Thermal (longwave) radiation is important for the radiative cooling process (Kiehl and Trenberth 1997) to balance the absorption of solar radiation. Here, we compile some recommendations on three major categories of estimation methods. The empirical method that combines the uses of satellite thermal data and atmospheric parameters is not perfect in extreme climate conditions ( $\mathrm{Yu}$ et al. 2014). Hence, the re-training of algorithm is recommended where the empirical method uses both thermal and atmospheric parameters. If the RTM uses the common calculation of all skies, the model performance degrades (Zhou et al. 2007). Therefore, separate calculation for clear and cloudy sky is suggested. In the case of hybrid method, some statistical algorithms frequently overestimate the longwave 
radiation over arid or desert surfaces where the ground-air temperature is high. Yu et al. (2013) used a correction method and found that the root means square error (RMSE) was substantially reduced. Therefore, a correction method is needed for model coefficients derivation from the ground-air temperature difference to reduce the overestimation of longwave radiation.

(3) Recommendations on ET estimation methods: ET is a vitally important component of terrestrial energy, water and bio-geophysical cycle. We make some important recommendations on various SEB-based ET estimation methods. The SEBI model is the surface temperature-based parametrisation scheme to estimate the location-dependent ET, where the use of air temperature at the top of atmospheric boundary layer is recommended instead of near surface temperature (Choudhury and Menenti 1993). Simplified SEBI (S-SEBI) is the maximum and minimum temperature-based estimation method, where no additional meteorological data are needed if the surface extremes (max and min of surface temperature) are available (Roerink et al. 2000). Hence, the desired satellite image should contain the extreme value of surface temperature. The SEBAL model is an iterative and feedbackbased numerical procedure that estimates surface fluxes using both the satellite and ground data. This model is widely accepted and recommended to use under several climatic conditions at both field and catchment scales for solving water resources and irrigation problems (Bastiaanssen et al. 2005). In SEBS, surface fluxes are estimated from satellite and ground data in terms of EF. This model is recommended to estimate ET for some special irrigation area such as Coleambally irrigation area (CIA) (Ma et al. 2013). The modified SEBS such as topographic enhanced SEBS (TESEBS) is suggested for areas with complex terrain (Chen et al. 2013; Amatya et al. 2015). The METRIC is an extension of SEBAL version with consideration of the slope aspect and is used for complex terrain areas with higher resolution satellite data (Carrillo-Rojas et al. 2016). This method is recommended for longer and higher mountainous areas with higher resolution satellite data. TSM model divides the composite radiometric temperature into two sources (soil and canopy), where overestimation occurs due to the uncertainties that arise from the determination of PT coefficients and iteration procedure (Yang et al. 2015). Here, the careful selection of target criteria is suggested for iteration process, and two observation periods are also recommended to perform the separate measurement of surface temperature.

However, the above complied recommendations can be applied properly on the following considerations: estimation manner (instantaneous/ continuous); study area's characteristics (land surface types, climate conditions); availability of satellite and ground data (spatial and temporal resolution, access criteria), etc.

\section{Conclusions and perspectives}

This paper reviews previous and recent studies on the estimation methods of the Earth's SEB components from ground and satellite measurements. We summarise the main scientific concepts, merits, demerits, errors and uncertainties of the studied methods and models and also provide some important recommendations to researchers on how to make use of these methods. In a broad sense, there has been a firm progress but this research area still faces many challenges.

The ground-based measurement instruments such as pyranometer, pyrgeometer, lysimeter, EC system and scintillometer have become more efficient and user friendly due to the rapid developments in electronics and communication technology. Therefore, the errors and uncertainties associated with ground measurements are negligible. But due to the limitation and lack of proper regional and global coverage, the worldwide ground measurement networks are not self-disciplined and unified. In the last three decades, satellite remote sensing technologies have developed significantly and the wide availability of satellite data products has enabled researchers to develop a wide spectrum of satellite-based estimation methods and models.

From this review work, we have observed that each method and model has its own advantages and disadvantages relative to other approaches, and there is no consensus on which one is the best. In reality, these are the important tools for estimating the SEB components at regional and global scales. There are several methods for satellite estimation of solar and thermal radiation. The RTM has a strong validity of physics (i.e., the RTM model 
follows the basic theory of radiation physics) and can be applied to all atmospheric and land surface profiles. Among other methods and parameterisation schemes, the use of hybrid method may achieve a better generalisation, which is highly expected for universal applications. Most of the SEB-based models are estimating latent heat or sensible heat fluxes as the residual of SEB by using satellite data and some additional ground-based meteorological data. No additional data are needed in the S-SEBI model if the surface extremes (max and min surface temperatures) are present in the satellite imagery. In SEBAL, it is required to determine a constant temperature for dry and wet conditions because the extreme temperatures vary with reflectance changes as a consequence of the dry and wet conditions. It has some important advantages such as minimum ground-based data and automatic internal calibration within each processed image. The SEBS estimates $H$ and LE distinctively under dry and wet limits in terms of EF for every pixel.

However, the accuracy of surface flux estimation using these methods varies from one model to another, one study area to another and one study period to another. Su et al. (2005) reported the accuracy of ET value estimated from SEBS was $10-15 \%$ with respect to ground-based measurement, where the EF ranged from 0.5 to 0.9. A maximum relative difference of $8 \%$ between measured and estimated EF was observed in the S-SEBI model (Roerink et al. 2000). The typical accuracy of SEBAL was tested under several climatic conditions at field scale and it was found to be $85 \%$ and $95 \%$ at daily and seasonal scales, respectively (Bastiaanssen 2000; Bastiaanssen et al. 2005). The SEBAL and SEBS have some limitations over mountainous area (Bastiaanssen et al. 2010; Chen et al. 2013). These limitations can be solved using METRIC and TESEBS models as they consider the slope aspect (Allen et al. 2007; Amatya et al. 2015). The TSM method is used for separate calculation of soil and canopy heat fluxes to improve the accuracy (Norman et al. 1995). Along with other uncertainties as described in the earlier section, uncertainties associated with the validation of satellite retrieved radiation quantities with the ground measurement are common in all satellite estimations. To overcome these uncertainties, the cross calibration within the same measurement network and among the different networks as well as the consistent processing and effective management of ground measurements is needed. Another difficulty is in the inter-comparison of the error calculations between ground and satellite estimation as they use different error measuring variables used in different studies such as bias, mean bias, mean absolute error, RMSE, percentage error, standard deviation, etc.

Although the reviewed methods and models demonstrate an enough capability for surface flux estimations, but still have some limitations which lead to errors and uncertainties. Therefore, future research can be focused on several directions. Newly developed methods in acquisition of satellite and ground data are needed to solve the addressed uncertainties and limitations. Hybrid methods or integration of some methods can be used to take the advantage of their respective merits and compensating for their limitations. The use of data fusion and data assimilation techniques can be highly useful for integrated estimations. The satellite estimation methods also have a large area to be improved for using the recent high-resolution satellite data as relevant satellite data are rapidly growing.

\section{Acknowledgements}

This study was financially supported by the National Key Research and Development Program of China (grant nos. 2016YFA0602302 and 2016YFB0502502). We also wish to acknowledge the intellectual and material contributions of CASTWAS President's Fellowship.

\section{References}

Allen R, Tasumi M and Trezza R 2007 Satellite-based energy balance for mapping evapotranspiration with internalized calibration (METRIC)-model; J. Irrig. Drain. Eng. 133 380-394.

Allen R, Burnett B, Kramber W H, Kjaersgaard J, Kilic A, Kelly C and Trezza R 2013 Automated calibration of the METRIC-landsat evapotranspiration process; J. Am. Water Resour. Assoc. 49 563-576.

Amatya P, Ma Y, Han C, Wang B and Devkota L 2015 Mapping regional distribution of land surface heat fluxes on the southern side of the central Himalayas using TESEBS; Theor. Appl. Climatol. 124 835-846.

Anderson M C, Norman J M, Mecikalski J R, Otkin J A and Kustas W P 2007 A climatological study of evapotranspiration and moisture stress across the continental United States based on thermal remote sensing: 1. Model formulation; J. Geophys. Res. Atmos. 112 D10117:1-D10117:17.

ASCE-EWRI 2005 The ASCE standardized reference evapotranspiration equation; ASCE-EWRI Standardization of 
Reference Evapotranspiration Task Committee Report, ASCE Reston, VA.

Augustine J, Hodges G, Cornwall C, Michalsky J and Medina C 2005 An update on SURFRAD - The GCOS surface radiation budget network for the continental United States; J. Atmos. Oceanic Technol. 22 1460-1472.

Baldocchi D, Falge E, Gu L, Olson R, Hollinger D, Running S, Anthoni A, Bernhofer C, Davis K, Evans R, Fuentes J, Goldstein A, Katul G, Law B, Lee X H, Malhi Y, Meyers T, Munger W, Oechel W, Pilegaard K and Wofsy S 2001 A new tool to study the temporal and spatial variability of ecosystem-scale carbon dioxide, water vapor, and energy flux densities; Bull. Am. Meteor. Soc. 82 2415-2434.

Barkstrom B R and Smith G L 1986 The earth radiation budget experiment: Science and implementation; Rev. Geophys. 24 379-390.

Baseline surface radiation network (n.d.) http://www.bsrn. awi.de/

Bastiaanssen W 1995 Regionalization of surface flux densities and moisture indicators in composite terrain; $\mathrm{PhD}$ Thesis, Wageningen Agricultural University, Wageningen, The Netherlands.

Bastiaanssen W 2000 SEBAL-based sensible and latent heat fluxes in the irrigated Gediz Basin Turkey; J. Hydrol. 229 $87-100$.

Bastiaanssen W, Menenti M, Feddes R and Holtslag A 1998a A remote sensing surface energy balance algorithm for land (SEBAL): 1. Formulation; J. Hydrol. 212-213 198212 .

Bastiaanssen W, Pelgrum H, Wang J, Ma Y, Moreno J, Roerink G and van der Wal T 1998b A remote sensing surface energy balance algorithm for land (SEBAL): 2. Validation; J. Hydrol. 212-213 213-229.

Bastiaanssen W, Noordman E, Pelgrum H, Davids G, Thoreson B and Allen R 2005 SEBAL model with remotely sensed data to improve water-resources management under actual field conditions; J. Irrig. Drain. Eng. 131 85-93.

Bastiaanssen W, Thoreson B, Clark B and Davids G 2010 Discussion of application of SEBAL model for mapping evapotranspiration and estimating surface energy fluxes in South-Central Nebraska by Ramesh K Singh, Ayse Irmak, Suat Irmak and Derrel L Martin; J. Irrig. Drain. Eng. 136 282-283.

Bonan G B 2008 Ecological Climatology: Concepts and Application; 2nd edn, Cambridge University Press, Cambridge, Chapter 1, pp. 1-24.

Bowen I S 1926 The ratio of heat losses by conduction and evaporation from any water surface; Phys. Rev. 27779 787.

Carlson T N, Gillies R R and Perry E M 1994 A method to make use of thermal infrared temperature and NDVI measurements to infer surface soil water content and fractional vegetation cover; Remote Sens. Rev. 9 161173.

Carrillo-Rojas G, Silva B, Córdova M, Célleri R and Bendix J 2016 Dynamic mapping of evapotranspiration using an energy balance-based model over an Andean Páramo Catchment of Southern Ecuador; Remote. Sens. (Basel) 8 160.

Chen X, Su Z, Ma Y, Yang K and Wang B 2013 Estimation of surface energy fluxes under complex terrain of
Mt. Qomolangma over the Tibetan Plateau; Hydrol. Earth Syst. Sci. 7 1607-1618.

Choudhury B and Menenti M 1993 Parameterization of land surface evaporation by means of location dependent potential evaporation and surface temperature range; Department for Environment, Food and Rural Affairs (Defra), London, UK, Vol. 212, pp. 561-568.

Cros S and Wald L 2003 Survey of the main databases providing solar radiation data at ground level; In: Proceedings of the 23rd EARSeL annual symposium remote sensing in transition (ed.) Goossens R I and Ghent, Belgium, pp. 491-497.

Dawson T E, Burgess S S O, Tu K P, Oliveira R S, Santiago L S and Fisher J B 2007 Nighttime transpiration in woody plants from contrasting ecosystems; Tree Physiol. 27 561575.

Diak G R, Mecikalski J R, Anderson M C, Norman J M, Kustas W P, Torn R D and Dewolf R L 2004 Estimating land surface energy budgets from space: Review and current efforts at the university review and current efforts at the University of Wisconsin-Madison and USDA-ARS; Bull. Am. Meteor. Soc. 85(1) 65-76.

Dutta D, Mahalakshmi D, Singh M, Goyal P, Paul S, Sharma $\mathrm{J}$ and Dadhwal V 2015 Satellite-Based estimation of instantaneous radiative fluxes over continental USA - A case study; J. Indian Soc. Remote Sens. 43(4) 1-9.

Ellingson R, Ferraro R and Gruber A 1983 An examination of a technique for estimating the longwave radiation budget from satellite radiance observations; Adv. Space Res. $\mathbf{2}$ $21-23$.

Fisher J, Tu K and Baldocchi D 2008 Global estimates of the land-atmosphere water flux based on monthly AVHRR and ISLSCP-II data, validated at 16 FLUXNET sites; Remote Sens. Environ. 112 901-919.

FLUXNET A Global Network (n.d.) https://fluxnet.ornl. gov/

Foken T 2008 The energy balance closure problem: An overview; Ecol. Appl. 18 1351-1367.

Gavilán P and Berengena J 2007 Accuracy of the Bowen ratio-energy balance method for measuring latent heat flux in a semiarid advective environment; Irrigation Sci. 25 127-140.

Gebler S, Hendricks Franssen H-J, Pütz T, Post H, Schmidt M and Vereecken H 2015 Actual evapotranspiration and precipitation measured by lysimeters: A comparison with eddy covariance and tipping bucket; Hydrol. Earth Syst. Sci. 19 2145-2216.

Gilgen H and Ohmura A 1999 The global energy balance archive; Bull. Am. Meteor. Soc. 80 831-850.

Global Energy and Water Cycle Exchange (n.d.) http:// www.gewex.org/

Guide to Meteorological Instruments and Methods of Observation (7th edn) 2008 https://www.wmo.int/pages/prog/ gcos/documents/gruanmanuals/CIMO/CIMO_Guide-7th_ Edition-2008.pdf

Ha W, Kolb T, Springer A, Dore S, O'Donnell F, Morales R, Lopez S M and Koch G 2015 Evapotranspiration comparisons between eddy covariance measurements and meteorological and remote-sensing-based models in disturbed ponderosa pine forests; Ecohydrology 8 1335-1350.

Harries J E, Russell J E, Hanafin J A, Brindley H, Futyan J, Rufus J, Kellock S, Matthews G, Wrigley R, Last A, 
Mueller J, Mossavati R, Ashmall J, Sawyer E, Parker D, Caldwell M, Allan R P, Smith A, Bates M J and Coan B 2005 The geostationary earth radiation budget project; Bull. Am. Meteor. Soc. 83 977-992.

Hartmann D 1994 Global Physical Climatology; International Geophysics Series Academic Press, London, UK, 56p.

Hena M, Ali M and Rahman M 2013 A simple statistical model to estimate incident solar radiation at the surface from NOAA AVHRR satellite data; Int. J. Inf. Technol. Comput. Sci. 02 36-41.

Huang G, Ma M, Liang S, Liu S and Li X 2011 A LUT based approach to estimate surface solar irradiance by combining MODIS and MTSAT data; J. Geophys. Res. 116 D22201:1-D22201:14.

Jackson R, Idso S and Reginato R P 1981 Canopy temperature as a crop water stress indicator; Water Resour. Res. 17 1133-1138.

Jacobowitz H and Tighe R 1984 The earth radiation budget derived from the Nimbus-7 ERB experiment; J. Geophys. Res. 89 4997-5010.

Jiao Z, Yan G, Zhao J, Wang T and Chen L 2015 Estimation of surface upward longwave radiation from MODIS and VIIRS clear-sky data in the Tibetan Plateau; Remote Sens. Environ. 162 221-237.

Kalma J D, McVicar T R and McCabe M F 2008 Estimating land surface evaporation: A review of methods using remotely sensed surface temperature data; Surv. Geophys. 29 421-469.

Kawai Y and Kawamura H 2005 Validation and improvement of satellite derived surface solar radiation over the northwestern Pacific Ocean; J. Oceanogr. 61 79-89.

Kiehl J T and Trenberth K E 1997 Earth's annual global mean energy budge; Bull. Am. Meteor. Soc. 78 197-208.

Kim D and Ramanathan V 2008 Solar radiation budget and radiative forcing due to aerosols and clouds; J. Geophys. Res. 113 D02203:1-D02203:34.

Krishnamurti T N and Biswas M K 2006 Transitions in the surface energy balance during the life cycle of a monsoon season; J. Earth Syst. Sci. 115(2) 185-201.

Kustas W 1990 Estimates of evapotranspiration with a one-layer and 2-layer model of heat-transfer over partial canopy cover; J. Appl. Meteorol. 29 704-715.

Kustas W and Norman J 1999 Evaluation of soil and vegetation heat flux predictions using a simple two-source model with radiometric temperatures for partial canopy cover; Agric. Forest. Meteorol. 94 13-29.

L'ecuyer T S, Beaudoing H K, Rodell M, Olson W, Lin B, Kato S, Clayson C A, Wood E, Sheffield J, Adler R, Huffman G, Bosilovich M, Gu G, Robertson F, Houser P R, Chambers D, Famiglietti J S, Fetzer E and Liu W T 2015 The observed state of the energy budget in the early twenty-first century; J. Clim. 28 8319-8346.

Lee M-I, Kang I-S and Kim J-K 2001 Influence of cloudradiation interaction on simulating tropical intraseasonal oscillation with an atmospheric general circulation model; J. Geophys. Res. 106 14,219-14,233.

Li F, Kustas W, Prueger J, Neale C and Jackson T 2005 Utility of remote sensing based two-source energy balance model under low and high vegetation cover conditions; J. Hydrometeorol. 6 878-891.

Li Z, Tang R, Wan Z, Bi Y, Zhou C, Tang B, Yan G and Zhang X 2009 A review of current methodologies for regional evapotranspiration estimation from remotely sensed data; Sensors 9 3801-3853.

Liang S, Zheng T, Liu R G, Fang H L, Tsay S C and Running S 2006 Estimation of incident photosynthetically active radiation from moderate resolution imaging spectrometer data; J. Geophys. Res. 111 D15208:1-D15208:13.

Liang S, Wang K and Wild X Z 2010 Review on estimation of land surface radiation and energy budgets from ground measurements, remote sensing and model simulations; IEEE J. Sel. Top. Appl. Earth Obs. Remote Sens. 3 225-240.

Lichun P, Wanbiao L, Jing Y, Dong C, Yuming L and Lijia C 2015 A review of parameterization methods for downward shortwave and longwave radiation on the surface; Acta Sci. Nat. Univ. Pekin. 51 772-782.

Liou Y-A and Kar S 2014 Evapotranspiration estimation with remote sensing and various surface energy balance algorithms - A review; Energies 7 2821-2849.

Liu Y, Hiyama T, Yasunari T and Tanaka H 2012 A nonparametric approach to estimating terrestrial evaporation: Validation in eddy covariance sites; Agric. Forest. Meteorol. 157 49-59.

Long C and Dutton E G 2002 BSRN Global Network recommended QC tests, V2.0; http://hdl.handle.net/10013/ epic.38770.d001

Lu N, Liu R, Liu J and Liang S 2010 An algorithm for estimating downward shortwave radiation from GMS 5 visible imagery and its evaluation over China; J. Geophys. Res. Atmos. 115 D18102:1-D18102:15.

Lu N, Qin J, Yang K and Sun J 2011 A simple and efficient algorithm to estimate daily global solar radiation from geostationary satellite data; Energy 36 3179-3188.

Ma Y and Pinker R T 2012 Modeling shortwave radiative fluxes from satellites; J. Geophys. Res. 117 D23202:1D23202:19.

Ma W, Hafeez M, Ishikawa H and Ma Y 2013 Evaluation of SEBS for estimation of actual evapotranspiration using ASTER satellite data for irrigation areas of Australia; Theor. Appl. Climatol. 112 609-616.

Main Geophysical Observatory, World Radiation Data Center, St. Petersburg, Russia, http://wrdc.mgo.rssi.ru

Meijninger W 2003 Surface fluxes over natural landscapes using scintillometry; PhD Thesis, Wageningen University, Wageningen, The Netherlands.

MODIS https://terra.nasa.gov/about/terra-instruments/ modis

Mueller R, Matsoukas C, Gratzki A and Hollmann R 2009 The CM-SAF operational scheme for the satellite based retrieval of solar surface irradiance - A LUT based eigenvector hybrid approach; Remote Sens. Environ. 113 1012-1024.

Nieveen J and Green A 1998 Measuring sensible heat flux over pasture using the Ct2 profile method; Bound. Layer Meteorol. 91 23-35.

Norman J, Kustas W and Humes K 1995 Source approach for estimating soil and vegetation energy fluxes in observations of directional radiometric surface temperature; Agric. Forest. Meteorol. 77 263-293.

Nouri H, Beecham S, Kazemi F and Hassanli A 2013 A review of ET measurement techniques for estimating the water requirements of urban landscape vegetation; Urban Water J. $10247-259$ 
Ohmura A, Dutton E G, Forgan B, Frohlich C, Gilgen, H, Hegner H, Heimo A, Konig-Langlo B, McArthur B, Muller G, Philipona R, Pinker R, Whitlock C H, Dehne K and Wild M 1998 Baseline surface radiation network (BSRN/WCRP): New precision radiometry for climate research; Bull. Am. Meteor. Soc. 79 2115-2136.

Pan X, Liu Y and Fan X 2016 Satellite retrieval of surface evapotranspiration with nonparametric approach: Accuracy assessment over a semiarid region; Adv. Meteorol. 2016, ID 1584316:1-ID 1584316:14.

Park M-S, Ho C-H, Cho H and Choi Y-S 2015 Retrieval of outgoing longwave radiation from COMS narrowband infrared imagery; Adv. Atmos. Sci. 32 375-388.

Paulescu M, Paulescu E, Gravila P and Badescu V 2013 Weather modeling and forecasting of PV systems operation; Springer-Verlag, London, Vol. XVIII, Chapter 2, pp. $20-24$.

Pauwels V and Samson R 2006 Comparison of different methods to measure and model actual evapotranspiration rates for a wet sloping grassland; Agric. Water Manag. 82 1-24.

Pinter P J Jr 1986 Effect of dew on canopy reflectance and temperature; Remote Sens. Environ. 19 187-205.

Pyrgeometer (n.d.) https://en.wikipedia.org/wiki/Pyrgeo meter

Renzullo L J, Barrett D J, Marks A S, Hill M J, Guerschman J P and Mu Q 2008 Multi-sensor model-data fusion for estimation of hydrologic and energy flux parameters; Remote Sens. Environ. 112 1306-1319.

Rigollier C, Lefèvre M and Wald L 2004 The method Heliosat-2 for deriving shortwave solar radiation from satellite images; Sol. Energy 77 159-169.

Roderick M L, Farquhar G D, Berry S L and Noble I R 2001 On the direct effect of clouds and atmospheric particles on the productivity and structure of vegetation; Oecologia 129 21-30.

Roerink G, Su Z and Menenti M 2000 S-SEBI: A simple remote sensing algorithm to estimate the surface energy balance; Phys. Chem. Earth B 25 147-157.

Ryu Y, Baldocchi D D, Kobayashi H, Ingen C V, Li J, Black T A, Beringer J, Gorsel E V, Knohl A, Law B E and Roupsard O 2011 Integration of MODIS land and atmosphere products with a coupled-process model to estimate gross primary productivity and evapotranspiratiom from $1 \mathrm{~km}$ to global scale; Global Biogeochem. Cycles 25 GB4017:1GB4017:24.

Samain B, Simons G, Voogt M, Defloor W, Bink N-J and Pauwels V 2012 Consistency between hydrological model, large aperture scintillometer and remote sensing based evapotranspiration estimates for a heterogeneous catchment; Hydrol. Earth Syst. Sci. 16 2095-2107.

Sanchez J, Kustas W, Caselles V and Anderson M 2007 Modelling surface energy fluxes over maize using a two-source patch model and radiometric soil and canopy temperature observations; Remote Sens. Environ. 112 1130-1143.

Schmetz J 1989 Towards a surface radiation climatology: Retrieval of downward irradiances from satellites; Atmos. Res. 23 287-321.

Schmetz J, Pili P, Tjemkes S, Just D, Kerkmann J, Rota S and Ratier A 2002 An introduction to Meteosat Second Generation (MSG); Bull. Am. Meteor. Soc. 83 977-992.

Schmithüsen H, Sieger R and König-Langlo G 2012 BSRN toolbox - A tool to create quality checked output files from BSRN datasets and station-to-archive files; Alfred Wegener Institute, Helmholtz Centre for Polar and Marine Research, Bremerhaven.

Schumacher C, Houze Jr R and Kraucunas I 2004 The tropical dynamical response to latent heating estimates derived from the TRMM precipitation radar; J. Atmos. Sci. 61 1341-1358.

Shang-Ping Xie, Kosaka Y and Okumura Y M 2016 Distinct energy budgets for anthropogenic and natural changes during global warming hiatus; Nat. Geosci. 929 33.

Shi T, Guan D, Wu J, Wang A, Jin C and Han S 2015 Comparison of methods for estimating evapotranspiration rate of dry forest canopy: Eddy covariance, Bowen ratio energy balance, and Penman-Monteith equation; J. Geophys. Res.: Atmos. 19 2145-2161.

Slingo A and Slingo J 1988 The response of general circulation model to cloud longwave radiative forcing. I: Introduction and initial experiments; Quart. J. Roy. Meteorol. Soc. 114 1027-1062.

Solar Instruments/Atmospheric Science Instruments, http://www.kippzonen.com/

Soumi NPP, https://www.nasa.gov/mission_pages/NPP/ main/index.html

Stephens G L and L'Ecuyer T 2013 The global energy balance from a surface prospective; Clim. Dyn. $403107-$ 3134.

Su Z 2002 The surface energy balance system (SEBS) for estimation of turbulent heat fluxes; Hydrol. Earth Syst. Sci. 6 85-99.

Su Z, Li X, Zhou Y, Wan L, Wen J and Sintonen K 2003 Estimating areal evaporation from remote sensing; Proc. IEEE Int. 2 1166-1168.

Su H, Mccabe M F, Wood E F, Su Z and Prueger J H 2005 Modeling evapotranspiration during SMACEX: Comparing two approaches for local- and regional-scale prediction; J. Hydrometeorol. 6 910-922.

Sun H A 2016 Two-source model for estimating evaporative fraction (TMEF) coupling Priestley-Taylor formula and two-stage trapezoid; Remote Sens. 8248.

Sun Z, Liu J, Zeng X and Liang H 2012 Parameterization of instantaneous global horizontal irradiance: Cloudy-sky component; J. Geophys. Res. 117 D14202:1-D14202:10.

Surface Radiation (SURFRAD) Network (n.d.) http://www. esrl.noaa.gov/gmd/grad/surfrad/

Tang Q, Peterson S, Cuenca R, Hagimoto Y and Lettenmaier D 2009 Satellite-based near-real-time estimation of irrigated crop water consumption; J. Geophys. Res. Atmos. 114 D05114:1-D05114:14.

Tang W, Qin J, Yang K, Liu S, Lu N and Niu X 2016 Retrieving high-resolution surface solar radiation with cloud parameters derived by combining MODIS and MTSAT data; J. Geophys. Res. Atmos. 16 2543-2557.

The Advanced Space-borne Thermal Emission and Reflection Radiometer, http://asterweb.jpl.nasa.gov/

The Clouds and the Earth's Radiant Energy System, http:// ceres.larc.nasa.gov/

The Geostationary Operational Environmental SatelliteAdvanced Baseline Imager(ABI), http://www.goes-r.gov/ spacesegment/abi.html

Trenberth K, Fasullo J and Kiehl J 2009 Earth's global energy budget; Bull. Am. Meteor. Soc. 90 311-323. 
Vázquez-Navarro M, Mayer B and Mannstein H 2013 A fast method for the retrieval of integrated longwave and shortwave top-of-atmosphere upwelling irradiances from MSG/SEVIRI (RRUMS); AMT 6 2627-2640.

Verstraete W, Veroustraete F and Feyen J 2005 Estimating evapotranspiration of European forests from NOAAimagery at satellite overpass time: Towards an operational processing chain for integrated optical and thermal sensor data products; Remote Sens. Environ. 96 256-276.

Wan Z, Zhang K, Xue X, Hong Z, Hong Y and Gourley J 2015 Water balance based actual evapotranspiration reconstruction from ground and satellite observations over the Conterminous United States; Water Resour. Res. 51 6485-6499.

Wang J and Bras R 2011 A model of evapotranspiration based on the theory of maximum entropy production; Water Resour. Res. 47 W03521:1-W03521:10.

Wang K and Liang S 2008 An improved method for estimating global evapotranspiration based on satellite determination of surface net radiation, vegetation index, temperature, and soil moisture; J. Hydrometeorol. 9712 727 .

Wang K and Liang S 2009 Global atmospheric downward longwave radiation over land surface under all-sky conditions from 1973 to 2008; J. Geophys. Res. Atmos. 114 D19101:1-D19101:12.

Wang W and Liang S 2010 A method for estimating clear-sky instantaneous land surface longwave radiation from GOES sounder and GOES-R ABI data; IEEE Geosci. Remote Sens. Lett. 7 708-712.

Wang H and Pinker R T 2009 Shortwave radiative fluxes from MODIS: Model development and implementation; J. Geophys. Res. 114 D20201:1-D20201:17.

Wang K, Wang P, Li Z, Cribb M and Sparrow M 2007 A simple method to estimate actual evapotranspiration from a combination of net radiation, vegetation index, and temperature; J. Geophys. Res. Atmos. 112 D15107:1D15107:14.

Wang P, Sneep M, Veefkind J, Stammes P and Levelt P 2014 Evaluation of broadband surface solar irradiance from the ozone monitoring instrument; Remote Sens. Environ. 149 88-99.

Ward H and Evans J G 2015 Infrared and millimetre-wave scintillometry in the suburban environment - Part 2: Large-area sensible and latent heat fluxes; Atmos. Meas. Tech. 8 1407-1424.
Wild M, Folini D, Schar C, Loeb N, Dutton E and Langlo G 2009 Earth global energy budget; Bull. Am. Meteor. Soc. 90 311-323.

World Climate Research Programme, http://www. wcrp-climate.org

Yan G, Wang T, Jiao Z, Mu X, Zhao J and Chen L 2016 Topographic radiation modeling and spatial scaling of clear-sky land surface longwave radiation over rugged terrain; Remote Sens. Environ. 172 15-27.

Yang Y, Long D, Guan H, Liang W, Simmons C and Batelaan O 2015 Comparison of three dual-source remote sensing evapotranspiration models during the MUSO EXE-12 campaign: Revisit of model physics; Water Resour. Res. 51 3145-3165.

Yeom J and Han K 2010 Improved estimation of surface solar insolation using a neural network and MTSAT-1R data; Comput. Geosci. 36 590-597.

Yingying C, Jiancheng S, Yuanyuan Q and Lingmei J 2008 The simulation study on land surface energy budget over China area based on Lis-Noah Land Surface Model; ISPRS, Beijing, Vol. XXXVII.

Yu S, Xin X and Liu Q 2013 Estimation of clear-sky longwave downward radiation from HJ-1B thermal data; Sci. China: Earth Sci. 56 829-842.

Yu S, Xin X and Zhang H 2014 Algorithms comparison for calculating downward longwave radiation by MODIS data under clear and cloudy skies; In: Proc. SPIE 9242924210.

Zelenka A, Perez R, Seals R and Renne D 1988 Effective accuracy of the satellite-derived hourly irradiance; Theor. Appl. Climatol. 62 199-207.

Zhang K, Kimball J S, Mu Q, Jones L A, Goetz S J and Running S W 2009 Satellite based analysis of northern ET trends and associated changes in the regional water balance from 1983 to 2005; J. Hydrol. 379 92-110.

Zhang X, Liang S, Zhou G, Wu H and Zhao X 2014 Generating global land surface satellite incident shortwave radiation and photosynthetically active radiation products from multiple satellite data; Remote Sens. Environ. 152 318-332.

Zhang K, Kimball J and Running S 2016 A review of remote sensing based actual evapotranspiration estimation; WIREs Water 3 834-853.

Zhou Y, Kratz D, Wilber A, Gupta S and Cess R 2007 An improved algorithm for retrieving surface downwelling longwave radiation from satellite measurements; J. Geophys. Res. 112 D15102:1-D15102:13. 